\title{
Transcriptional profiling of the response to the trichloroethylene metabolite $S$-(1,2-dichlorovinyl)-L-cysteine revealed activation of the elF2a/ATF4 integrated stress response in two in vitro placental models
}

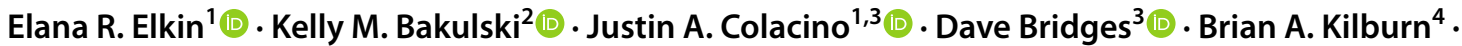 \\ D. Randall Armant ${ }^{4,5}$ (D) Rita Loch-Caruso ${ }^{1}$ (i)
}

Received: 21 September 2020 / Accepted: 25 February 2021 / Published online: 16 March 2021

(c) The Author(s), under exclusive licence to Springer-Verlag GmbH Germany, part of Springer Nature 2021

\begin{abstract}
Trichloroethylene (TCE) is an industrial solvent and widespread environmental contaminant. Although TCE exposure is prevalent, epidemiological studies of TCE exposure associations with adverse birth outcomes are inconclusive. Prior studies show that the TCE metabolite $S$-(1,2-dichlorovinyl)-L-cysteine (DCVC) exhibits toxicity in a placental cell line. In the current study, genome-wide gene expression and gene set enrichment analyses were used to identify novel genes and pathway alterations in the HTR-8/SVneo human trophoblast cell line and human placental villous explants treated with DCVC at concentrations relevant to human exposures. In the cells, concentration- and time-dependent effects were observed, as evidenced by the magnitude of altered gene expression after treatment with $20 \mu \mathrm{M}$ DCVC versus $10 \mu \mathrm{M}$, and 12-h versus 6-h of treatment. Comparing the two models for the transcriptional response to 12-h $20 \mu \mathrm{M}$ DCVC treatment, no differentially expressed genes reached significance in villous explants, whereas 301 differentially expressed genes were detected in HTR-8/SVneo cells compared with non-treated controls (FDR $<0.05+\operatorname{LogFC}>0.35$ [FC $>1.3]$ ). GSEA revealed five upregulated enriched pathways in common between explants and cells (FDR $<0.05$ ). Moreover, all 12-h DCVC treatment groups from both models contained upregulated pathways enriched for genes regulated by the ATF4 transcription factor. The overrepresentation of ATF4 regulation of differentially expressed genes indicated activation of the integrated stress response (ISR), a condition triggered by multiple stress stimuli, including the unfolded protein response. DCVC-induced ISR activation was confirmed by elevated eIF2 $\alpha$ phosphorylation, ATF4 protein concentrations, and decreased global protein synthesis in HTR-8/SVneo cells. This study identifies a mechanism of DCVC-induced cytotoxicity by revealing the involvement of a specific stress signaling pathway.
\end{abstract}

Keywords Trichloroethylene $\cdot$ S-(1,2-dichlorovinyl)-1-cysteine (DCVC) $\cdot$ Placenta $\cdot$ Integrated stress response $\cdot$ ATF4

\section{Introduction}

Elana R. Elkin

elkinela@umich.edu

1 Department of Environmental Health Sciences, University of Michigan, 1415 Washington Heights, Ann Arbor, MI 48109-2029, USA

2 Department of Epidemiology, University of Michigan, Ann Arbor, MI, USA

3 Department of Nutritional Sciences, University of Michigan, Ann Arbor, MI, USA

4 Department of Obstetrics and Gynecology, Wayne State University School of Medicine, Detroit, MI, USA

5 Department of Anatomy and Cell Biology, Wayne State University School of Medicine, Detroit, MI, USA
Trichloroethylene (TCE) is a volatile organic compound that belongs to a class of chlorinated hydrocarbons with potent solvent properties. Throughout the twentieth century, the chemical was widely used as a dry cleaning solvent and vapor metal degreaser with little attention paid to disposal methods (Chiu et al. 2013; Waters et al. 1977). Despite substantial efforts in recent decades to clean up and prevent further TCE environmental contamination, legacy pollution of soil and groundwater remains, as evidenced by TCE detection in thousands of hazardous waste sites across the United States (U.S. EPA (Environmental Protection Agency) 2019a; U.S. EPA (Environmental 
Protection Agency) 2019b). Due to ongoing usage and persistent environmental contamination, occupational and community-based TCE exposure in humans is widespread.

TCE exposure during pregnancy is associated with adverse birth outcomes, including multiple measures of restricted (or reduced) fetal growth (Forand et al. 2012; Ruckart et al. 2014). In rats, TCE treatment during midgestation decreases fetal weight and elevates oxidative stress biomarkers in the placenta (Loch-Caruso et al. 2019). Despite links between TCE exposure and elevated risks of adverse birth outcomes in humans and rats, the underlying toxicological mechanisms of these associations have scarcely been explored, as previously reviewed by Elkin et al. (2020c). The placenta, the multifaceted organ that supports the fetus during pregnancy, is at risk of TCEinduced toxic injury because it is capable of metabolizing TCE to its reactive metabolites (Burton and Fowden 2015), and is likely in direct contact with the chemical and its metabolites circulating in maternal blood (Laham 1970). Indeed, one study reported TCE blood concentration levels of approximately $2 \mathrm{mg} / \mathrm{L}$ in females volunteers exposed to $100 \mathrm{ppm}$ TCE for $4 \mathrm{~h}$ via inhalation (Fisher et al. 1998).

Placental development during the first trimester is especially vulnerable to xenobiotic insult because the first trimester encompasses a critical window for establishing adequate maternal blood supply to the placental bed. Fetal origin extravillous trophoblasts are specialized placental cells that play a critical role in placentation. During the first trimester, these cells acquire an invasive phenotype and migrate into the maternal decidua from the chorionic villi. Once in the decidua, the cells facilitate remodeling of the spiral arteries necessary for increased maternal blood supply to the placenta (Burton and Jauniaux 2015; Pijnenborg et al. 1981). Furthermore, as the pregnancy progresses to the second and third trimesters, the extravillous trophoblasts form cell columns at the tips of chorionic villi that anchor the villi to the maternal basal plate and stabilize them in the intervillous space (Kaufmann and Castellucci 1997). Dysfunctional trophoblasts may jeopardize the maternal blood supply to the placenta and result in abnormal placental development. Moreover, placental insufficiency, a condition caused in part by inadequate spiral artery remodeling, may contribute to intrauterine growth restriction (Burton and Jauniaux 2015), preterm birth (Morgan 2014) and pre-eclampsia (Brosens et al. 1972; Steegers et al. 2010).

The TCE glutathione conjugation-derived metabolite $S$-(1,2-dichlorovinyl)-L-cysteine (DCVC) induces cytotoxicity in HTR-8/SVneo, a placental cell line that models first-trimester extravillous trophoblasts (Elkin et al. 2020a; Hassan et al. 2016). However, prior mechanistic studies of DCVC-induced cytotoxicity in placental cells have focused on specific molecular signaling pathways and biological responses, including reactive oxygen species generation, lipid peroxidation, inflammatory responses, mitochondrial dysfunction and apoptotic signaling (Elkin et al. 2019, 2018; Hassan et al. 2016). Application of comprehensive discovery approaches such as genome-wide gene expression profiling allows for the unbiased characterization of toxicity mechanisms without relying on individual pre-selected pathways and/or processes.

In the current study, high throughput RNA sequencing was used to quantify genome-wide DCVC-induced differential gene expression in two different first trimester placental models in vitro. The HTR-8/SVneo cells, with an extravillous trophoblast phenotype, were used to evaluate transcriptional responses in this specific critical cell type. Villous explants from first trimester placentae were used to evaluate transcriptional responses in intact villi tissue with multiple interacting cell types, including extravillous trophoblasts. Both of these placental models have been used extensively to study placental biology and pathophysiology (Huckle 2017; Orendi et al. 2011) and to study the effect of xenobiotics on the placenta (Kovo and Golan 2008). Subsequently, gene set enrichment testing was used to identify biological pathways and/or processes targeted by DCVC and re-evaluate previously identified pathways. The most notable pathway identified was the endoplasmic reticulum unfolded protein response (UPR), a cellular response designed to rid cells of accumulated misfolded proteins in the endoplasmic reticulum (ER). Upon further characterization of genes enriched in this pathway, the specific involvement of the integrated stress response (ISR), a condition triggered by the UPR and other stress stimuli, was revealed (Pakos-Zebrucka et al. 2016). Because the ISR is characterized by eIF $2 \alpha$ phosphorylation, causing protein synthesis restriction and selective activation of transcription factor 4 (ATF4)-mediated upregulation of amino acid biosynthesis and transport genes (Pakos-Zebrucka et al. 2016), additional experiments were conducted to confirm ISR activation by measuring global protein synthesis, phosphorylation levels of eIF $2 \alpha$ and protein concentrations of ATF4 as key regulators of ISR activation. Lastly, cell cycle progression and proliferation were determined in the cell model to evaluate functional consequences of DCVC treatment and ensure no acute cellular toxicity.

\section{Materials and methods}

The overall experimental design is outlined in Fig. 1. The effects of DCVC on gene expression were determined in placental villous explants and HTR-8/SVneo cells using RNA sequencing and gene set enrichment analysis. Followup experiments were conducted to verify the affected genes and pathways in HTR-8/SVneo cells. 


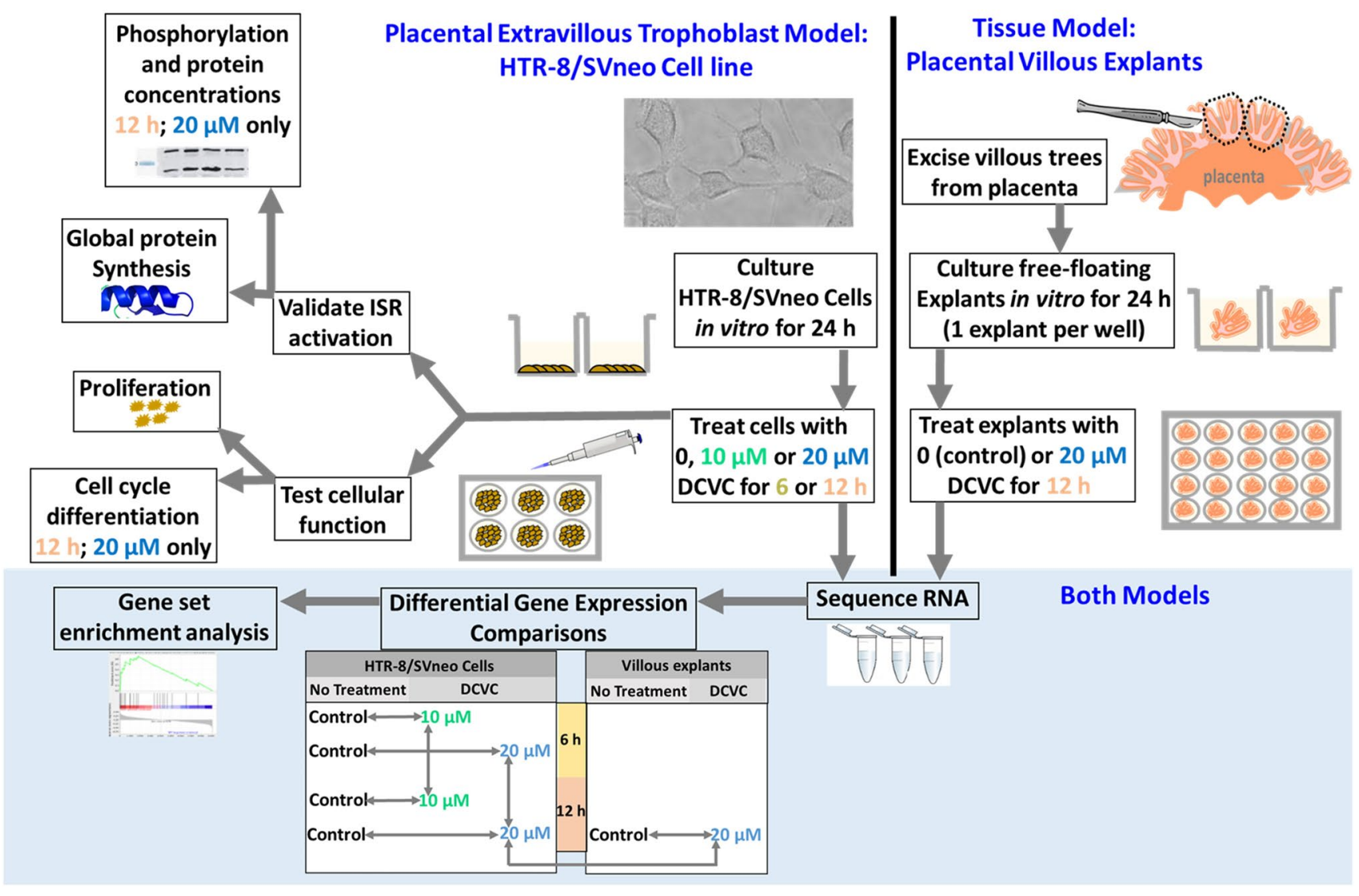

Fig. 1 Overall experimental design. HTR-8/SVneo cells and villous explant tissues were exposed to 0,10 or $20 \mu \mathrm{M}$ DCVC for 6 or $12 \mathrm{~h}$. RNA sequencing and gene set enrichment analysis were performed to

\section{Tissue and cell culture reagents}

Cell and tissue culture reagents including RP mine and without phenol red, advanced DMEM/F-12 culture medium, $10,000 \mathrm{U} / \mathrm{mL}$ penicillin and $10,000 \mu \mathrm{g} / \mathrm{mL}$ streptomycin $(\mathrm{P} / \mathrm{S})$ mixed solution, Antibiotic-Antimycotic (Anti-Anti) mixed solution and fetal bovine serum (FBS) were purchased from Gibco, a division of Thermo Fisher Scientific (Waltham, MA, USA). Phosphate buffered saline (PBS) and $0.25 \%$ trypsin were purchased from Invitrogen Life Technologies (Carlsbad, CA, USA).

The TCE metabolite $S$-(1, 2-dichlorovinyl)-L-cysteine (DCVC) was synthesized as a powder by the University of Michigan Medicinal Chemistry Core according to published procedures (McKinney et al. 1959). Purity of $98.7 \%$ was measured using high-performance liquid chromatography analysis. A stock solution of $1 \mathrm{mM}$ DCVC was prepared by dissolving DCVC powder in PBS. The chemical structure was confirmed periodically by nuclear magnetic resonance analysis MI 1640 culture medium with L-glutamine performed at the University of Michigan Biochemical Nuclear identify novel genes and pathways affected by DCVC treatment. Follow-up experiments were conducted to verify the affected genes and pathways in HTR-8/SVneo cells

Magnetic Resonance Core. The DCVC stock solution was stored in aliquots at $-20^{\circ} \mathrm{C}$ until use.

\section{Cell culture}

HTR-8/SVneo cells, a gift from Dr. Charles H. Graham (Queen's University, Kingston, Ontario, Canada), were cultured as previously described (Graham et al. 1993; Hassan et al. 2016; Tetz et al. 2013). Briefly, cells were cultured between passages 78-84 in RPMI 1640 medium supplemented with $10 \%$ FBS and $1 \% \mathrm{P} / \mathrm{S}$ at $37{ }^{\circ} \mathrm{C}$ in a $5 \% \mathrm{CO}_{2}$ humidified incubator. Cells were cultured in RPMI 1640 growth medium with $10 \% \mathrm{FBS}$ and $1 \% \mathrm{P} / \mathrm{S}$ prior to and during experiments to ensure optimal cell growth as previously described by Graham et al. (Graham et al. 1993). Cells were grown to $70-90 \%$ confluence at least $24 \mathrm{~h}$ after plating prior to use in any experiments. For gene expression experiments, cells were seeded at a density of 800,000 cells per well in 6-well cell culture plates. $24 \mathrm{~h}$ later, cells were treated with RPMI 1640 complete medium alone (control) or complete medium plus DCVC diluted to a final concentration of 10 or 
$20 \mu \mathrm{M}$ for 6 or 12 h. Four independent biological replicate experiments were performed.

\section{Cell line validation}

Microsatellite genotyping via fragment analysis was performed using AmpFLSTR Identifiler Plus PCR Amplification Kit run on an 3730XL Genetic Analyzer (Applied Biosystems; Waltham, MA, USA). DNA for 8 tetranucleotide repeat loci and the Amelogenin sex determination marker were identified. The short tandem repeat profile generated for our cells was compared to the short tandem repeat profile for cells identified as HTR-8/SVneo (ATCC ${ }^{\circledR}$ CRL-3271 ${ }^{\mathrm{TM}}$ ) by ATCC $^{\circledR}(2015)$ (Manassas, VA, USA). The short tandem repeat profile was an exact match: CSF1PO: 12, D13S317: 9,12, D16S539: 13D5S818: 12, D7S820: 12, TH01: 6,9.3, vWA: 13,18, TPOX: 8, Amelogenin sex determination marker: X (ATCC 2015).

\section{Explant tissue procurement and culture}

First-trimester placental tissues $(N=5 ; 4$ male and 1 female) ranging in gestational age from 8.4 to 11 weeks (mean $=9.68 \pm 0.98$ weeks) were acquired as discarded tissues at the time of termination at a Michigan family planning clinic with Institutional Review Board approval (Wayne State University IRB\# 013515MP4E) and written informed consent obtained by collaborating Wayne State University physicians. Tissues were transported to the laboratory in ice-cold PBS. Chorionic villi were dissected under a microscope into approximately $20 \mathrm{mg}$ (wet) segments and cultured in DMEM/ F12 supplemented with 10\% FBS and 1\% Anti-Anti. The villous segments were floated one per well in clear 24-well cell culture plates and allowed to acclimate in a $5 \% \mathrm{CO}_{2}$ humidified incubator for $24 \mathrm{~h}$, as previously described (Bolnick et al. 2017). For gene expression experiments, the culture medium was removed and explants were treated with fresh DMEM/ F12 complete medium alone (control) or complete medium plus DCVC diluted to a final concentration of $20 \mu \mathrm{M}$, and then cultured for an additional $12 \mathrm{~h}$. Five independent biological replicate experiments were performed using placentae from 5 different donors on different days. Each experiment was conducted with a placenta from a different donor, and villous explants from the same placenta were assigned randomly to the non-treated control and DCVC-exposed groups.

\section{Cell and tissue toxicant treatment}

Prior to each experiment, a DCVC stock solution aliquot was thawed in a $37{ }^{\circ} \mathrm{C}$ water bath and then diluted in DMEM/ F12 supplemented with 10\% FBS and 1\% Anti-Anti (villous explants) or RPMI 1640 supplemented with 10\% FBS and $1 \% \mathrm{P} / \mathrm{S}$ (HTR-8/SVneo) to final concentrations of 10 or $20 \mu \mathrm{M}$ DCVC. PBS alone was used as the $0 \mu \mathrm{M}$ DCVC negative control. These concentrations of DCVC were chosen because we previously demonstrated that they did not induce cytotoxicity at the time points used in the current study (Elkin et al. 2020a, 2019, 2018; Hassan et al. 2016). Moreover, these concentrations are comparable to the average concentration of the DCVC precursor $S$-(1,2-dichlorovinyl) glutathione (DCVG), $13.4 \mu \mathrm{M}$, measured in the serum of female volunteers exposed to $100 \mathrm{ppm}$ of the parent compound, TCE, by inhalation for $4 \mathrm{~h}$ (Lash et al. 1999).

\section{Cell cycle phase determination}

HTR-8/SVneo cells were seeded at a density of 400,000 cells per well in a 6-well plate and allowed to adhere for $24 \mathrm{~h}$ prior to treatment. Cells were treated for $12 \mathrm{~h}$ with medium alone (control) or DCVC $(10$ or $20 \mu \mathrm{M})$. The percentage of cells in each well in $G_{1} / G_{0}, S$, and $G_{2} / M$ phases were measured using the Cell Cycle Phase Determination Kit (Cayman Chemical; Ann Arbor, MI, USA) and flow cytometry, performed according to the manufacturer's protocol. This assay uses propidium iodide (PI) to label DNA. Briefly, after exposure, cells were treated with $0.25 \%$ trypsin-EDTA and incubated for 2 min to detach adherent cells from the substrate. After incubation, trypsin was deactivated with FBS-containing medium, and the suspended cells were transferred to 5-ml round-bottom fluorescence-activated cell sorting (FACS) tubes. Cells were washed twice with $1 \mathrm{ml}$ of assay buffer, resuspended in $500 \mu \mathrm{l}$ of cell fixative assay buffer solution, and chilled for $2 \mathrm{~h}$ at $-20^{\circ} \mathrm{C}$. After fixation, cells were washed and resuspended in $500 \mu \mathrm{l}$ PI staining solution, incubated for $30 \mathrm{~min}$ at room temperature, and transported to the University of Michigan Flow Cytometry Core for analysis. Cell phases were quantified using a LSRFortessa Flow Cytometer (BD Biosciences; San Jose, CA, USA). Quantification and dye-based visualization were performed using BD FACSDiva Software (BD Sciences). Cell aggregates and cellular debris were excluded using the forward scatter (FSC) and side scatter (SSC) modes and the analysis was performed using 10,000 events per sample. PI was detected using the $488 \mathrm{~nm}$ laser.

\section{Cell proliferation measurement}

HTR-8/SVneo cells were seeded at a density of 10,000 cells per well in a 96-well plate and allowed to adhere for $24 \mathrm{~h}$. Cells were then treated with medium alone (control) or DCVC $(10$ or $20 \mu \mathrm{M})$ in quintuplicate for 6 or $12 \mathrm{~h}$. CyQUANT $^{\circledR}$ Cell Proliferation Assay (Invitrogen) was used to quantify cell proliferation. The stain specifically binds to cellular DNA, and the fluorescence is proportional to the number of cells. The assay was performed according to the manufacturer's protocol. Briefly, dye binding solution was prepared by diluting CyQUANT ${ }^{\circledR}$ reagent in 
Hank's Balanced Salt Solution (HBSS). After exposure to DCVC, the growth medium was removed and CyQUANT ${ }^{\circledR}$ dye binding solution was added to each well. Cells were incubated for $1 \mathrm{~h}$ at $37{ }^{\circ} \mathrm{C}$. After incubation, fluorescence was measured (excitation: $485 \mathrm{~nm}$; emission $530 \mathrm{~nm}$ ) using a SpectraMax M2e Multi-Mode Microplate Reader (Molecular Devices).

\section{RNA isolation}

\section{HTR-8/SVneo cells}

After exposure, cells were scraped and lysed with RLT lysis buffer containing beta-mercaptoethanol. Cell lysates were homogenized using QIA shredders (Qiagen), and mRNA was extracted using the RNeasy Plus Mini Kit (Qiagen) following the manufacture's recommended protocol. RNA concentrations were determined with a Nanodrop 1000 Spectrophotometer (Thermo Fisher Scientific) and stored at $-80{ }^{\circ} \mathrm{C}$. RNA was transported on dry ice to the University of Michigan Advanced Genomics Core for further processing. Four independent experiments were performed. Each treatment group within a given experiment was performed in triplicate. RNA from triplicates were pooled according to the treatment group within the experiment. In total, RNA was analyzed from 24 cell samples: 4 replicates at 2 time points and 3 treatment groups.

\section{Placental villous explants}

After the treatment period, each explant was transferred to a 1.5-mL microcentrifuge tube, lysed in QIAzol reagent and homogenized in a TissueLyser LT (Qiagen) for $5 \mathrm{~min}$ at $50 \mathrm{~Hz}$, using one $3.2 \mathrm{~mm}$ stainless steel bead per tube. mRNA was extracted using the miRNeasy Mini Kit (Qiagen) following the manufacturer's recommended protocol. RNA was eluted in RNase-free water. RNA concentrations were determined with a Nanodrop 1000 Spectrophotometer (Thermo Fisher Scientific) and stored at $-80{ }^{\circ} \mathrm{C}$. RNA was transported on dry ice to the University of Michigan Advanced Genomics Core for further processing. Each treatment group within a given experiment $(N=5)$ was performed in triplicate ( 3 separate villous explants from the same placenta). RNA from triplicates were pooled according to the treatment group within the experiment. In total, RNA was analyzed from 10 explant samples (5 placentas and with 2 treatment groups).

\section{RNA sequencing}

At the University of Michigan Advanced Genomics Core, mRNA concentrations and quality were evaluated using a
Bioanalyzer instrument (Agilent; Santa Clara, CA, USA). Stranded sequencing libraries for RNA isolated from HTR-8/ SVneo cells were prepared with the TruSeq Stranded mRNA Library Prep Kit (lllumina; San Diego, CA, USA). Libraries were sequenced (on one lane) using single-end 50 cycle reads on a HiSeq 4000 sequencer (lllumina). The average total number of reads per sample for HTR-8/SVneo cells was $26,515,09$. Stranded sequencing libraries for RNA isolated from villous explants were prepared with the KAPA Stranded RNA-Seq Kit with RiboErase (Roche; Basel, Switzerland). Libraries were multiplexed (on two lanes) and sequenced using single-end 50 cycle reads on a HiSeq 4000 sequencer (lllumina). The average total number of reads per sample was $13,368,165$.

\section{RNA sequencing data analyses}

The Flux high-performance computer cluster at the University of Michigan was used for computational analysis. Sequencing read quality was assessed using FastQC (Andrews 2010). Reads were aligned to the human genome using STAR (Dobin et al. 2013), with the options "outFilterMultimapNmax 10" and "sjdbScore 2". Aligned reads were assigned to GRCh37 genes using featureCounts (Liao et al. 2014). HTR-8/SVneo had $85.38 \%$ uniquely mapped reads. Villous explants had $82.46 \%$ uniquely mapped reads. Prior to differential gene expression testing, genes with mean read counts-per-million less than four (HTR-8/SVneo) or five (explants) across all samples were filtered out and excluded from the analysis to reduce dispersion due to low expression levels. After filtering, 12,855 (HTR-8/SVneo) or 13,972 (explants) genes were included in the analyses. Data were normalized using the trimmed mean of $\mathrm{M}$ values (TMM) method (Robinson and Oshlack 2010). Differential gene expression testing was performed using the edgeR package (version 3.1) for R statistical computing (Robinson et al. 2010). Quasi-likelihood general linear modeling was used for differential gene expression testing (Lun et al. 2016). For HTR-8/SVneo cells, comparisons were made within each time point between 0 (control) and 10 or $20 \mu \mathrm{M}$ DCVC, respectively, adjusting for experiment day as a covariate using the glmQLFit function in edgeR. For villous explants, comparisons were made between 0 (control) and $20 \mu \mathrm{M}$ DCVC, adjusting for a placental donor as a covariate. The $\log _{2}$ fold change/fold change values reported for each gene were calculated from normalized (TMM method) gene expression counts averaged from each matching treatment/exposure replicate and directly compared to the average normalized gene expression counts of time-matched controls. Genes were considered differentially expressed between non-treated and treated samples with an adjusted $p$-value $<0.05$ using the Benjamini-Hochberg false discovery rate (FDR) method (Benjamini and Hochberg 1995). 
DCVC-induced upregulation $>1.3$-fold or downregulation $<-1.3$-fold are denoted throughout the results section. These fold-change (FC) values equate to $\log _{2}$ fold-change $(\log \mathrm{FC})>0.35$ (upregulation) or $<-0.35$ (downregulation). We selected a relatively inclusive $\log _{2}$ fold change threshold to facilitate discussion of our genome-wide discovery results. This selection was a balance of prioritizing genes with larger comparative gene expression changes, while still conducting a thorough evaluation of differential gene expression. Moreover, we conducted sensitive analyses to demonstrate that using a more conservative $\log \mathrm{FC}$ cutoff does not change the overall conclusions of the paper (Suppl. Table 7).

Multidimensional scaling (MDS) plots constructed from RNA expression data were used to observe how samples, treated or non-treated from each respective experiment, clustered on relevant covariates including treatment, treatment duration and experimental day (HTR-8/SVneo cells), or treatment, sex, gestational week, and donor placenta (explants). Student's t-test (for two groups) or one-way ANOVA (for three or more groups) were used to test for associations between covariates and MDS dimension 1 or 2 .

\section{Correlation and linear regression testing}

To compare the effects of DCVC across time (6 vs. $12 \mathrm{~h}$ ), dose (10 $\mu \mathrm{M}$ vs. $20 \mu \mathrm{M}$ DCVC), or model system (villous explants vs. HTR-8/SVneo), differential gene expression patterns were tested for correlation. Across all genes tested, Pearson's correlation coefficients were calculated and linear regression models were fitted. Comparisons were tested within each time point between non-treated controls and 10 or $20 \mu \mathrm{M}$ DCVC using $\log F C$ values for 12,855 genes. Likewise, comparisons were tested between non-treated controls and each DCVC concentration for 6 or $12 \mathrm{~h}$ of exposure, also using $\log$ FC values for 12,855 genes. Lastly, comparisons were tested between placental villous explants and HTR-8/ SVneo cells each exposed to $20 \mu \mathrm{M}$ DCVC for $12 \mathrm{~h}$ using $\log \mathrm{FC}$ values for 11,912 commonly expressed genes.

\section{Gene set enrichment analyses}

To identify biological pathways and processes impacted by DCVC treatment, gene set enrichment analyses were performed using GSEA software (Mootha et al. 2003; Subramanian et al. 2005). For each gene set within a specified Molecular Signatures Database (MSigDB, RRID: SCR_016863, version 7.0) curated collection, we used GSEA pre-ranked analyses to compute permutation-based tests that calculate a Normalized Enrichment Score (NES) and statistical FDR (Benjamini and Hochberg 1995; Liberzon et al. 2011). Additionally, the GSEA analyses returned a list of enriched genes for each gene set based on differential gene expression. The enriched gene list for a gene set was derived from all genes annotated to that gene set. Here, the hallmark gene set collection was used in the analyses because it represents welldefined biological pathways, processes and states with strong gene expression concordance and reduced redundancy often seen within other collections (Liberzon et al. 2015). To conduct separate analyses for HTR-8/SVneo cells and placental villous explants, 12,855 (HTR-8/SVneo) or 13,972 (villous explants) genes included in the differential gene expression tests, respectively, were pre-ranked according to the $\log F C$ value for each gene. All genes (regardless of FDR or $\log _{2}$ fold change values) thus, cutoffs do not impact the enriched pathways. We used 1000 permutations to test for enrichment within each of the hallmark gene sets. Because our genes were ranked based on $\log \mathrm{FC}$ values, the magnitude of the NES above or below 0 corresponds directly with DCVCinduced up-regulation or down-regulation, respectively, of an enriched pathway or process. Gene sets representing an FDR $<0.05$ were considered significantly enriched (positive or negative).

\section{Evaluation of temporal patterns in regulation of gene expression in HTR-8/SVneo}

Differentially expressed genes with a logFC magnitude difference $>0.35$ were grouped together by treatment based on temporal expression patterns (upregulated, downregulated or no change) for the two treatment durations (6 and $12 \mathrm{~h}$ ). There were a total of 8 groups within each DCVC concentration: consistent responders (up $\rightarrow$ up and down $\rightarrow$ down) temporary responders (up $\rightarrow$ down, and down $\rightarrow$ up) early responders (down $\rightarrow$ no change and up $\rightarrow$ no change), late responders (no change $\rightarrow$ up and no change $\rightarrow$ down. Groups that contained $>100$ genes were tested for enrichment on the Enrichr platform (RRID: SCR_001575) (Chen et al. 2013; Kuleshov et al. 2016) for transcription factors (TRRUST) (Han et al. 2018) and histone modifications (ENCODE-2015) (Davis et al. 2018; Encode Project Consortium 2012).

\section{Enrichment testing and visualization of ATF4 gene targets from HTR-8/SVneo RNA sequencing analysis}

Because ATF4-driven transcriptional activity is a key indicator of ISR activation, ATF4 gene targets, were tested for overrepresentation among DCVC-induced differentially expressed genes. Individual ATF4 gene targets were identified from a mouse model ChIP-seq analysis and included in our study (Han et al. 2013). Two additional ATF4 gene targets, PMAIP1 and PSPH, were also included (Sharma et al. 2018; Yang et al. 2018; Zhao et al. 2014). Genes regulated by ATF4 $(N=383)$ were tested for enrichment in DCVCtreated HTR-8/SVneo genes with significant differential expression $(\mathrm{FDR}<0.05+\operatorname{LogFC}>0.35[\mathrm{FC}>1.3])$. ATF4 
mouse target genes were converted to human homologues using the biomaRt package (Durinck et al. 2005, 2009). ATF4 target gene enrichment tests were performed using the phyper function (hypergeometric test) (R Core Team 2019). To visualize significantly enriched individual differential gene expression for ATF4 targets from the RNA sequencing analyses, a heatmap displaying the $\log F C$ levels of treated compared to control samples, along with a hierarchical clustering diagram were generated using the heatmap. 2 function in the gplots package (Warnes et al. 2019).

\section{Western blotting analyses}

HTR-8/SVneo cells were seeded at a density of 400,000 cells per well in a clear 6-well culture plate and allowed to adhere for $24 \mathrm{~h}$. Cells were treated with medium alone (control) or DCVC $(20 \mu \mathrm{M})$ for $12 \mathrm{~h}$. Cells were lysed in RIPA lysis buffer containing both protease and phosphatase inhibitors or protease inhibitors alone and then centrifuged at $14,000 \times g$ for $10 \mathrm{~min}$ at $4{ }^{\circ} \mathrm{C}$. Lysates were heated with loading buffer at $85{ }^{\circ} \mathrm{C}$ for $2 \mathrm{~min}$. Samples were loaded into commercially available Novex 4-20\% Tris-Glycine Mini Gel cassettes (Invitrogen) and proteins were separated by polyacrylamide gel electrophoresis run at $140 \mathrm{~V}$ for $1.5 \mathrm{~h}$. SeeBlue Plus 2 pre-stained protein standard (Invitrogen) was used as a reference for protein molecular weight. After separation, proteins were transferred to nitrocellulose membranes at $75 \mathrm{~V}$ for $4 \mathrm{~h}$ at $4{ }^{\circ} \mathrm{C}$. Membranes were first blotted with Revert Total Protein Stain (Li-Cor Biosciences) and washed with Revert wash. Membranes were then blotted at room temperature using ATF4 (molecular weight 49; catalog no. 11815; Cell Signaling Technologies; RRID: AB_2616025), and eukaryotic initiation factor 2 alpha subunit -phosphorylated (p-eIF $2 \alpha$ ) or non-phosphorylated (eIF2 $\alpha$ ) [molecular weight 38; catalog nos. 3597 or 9722; Cell Signaling Technologies; Research Resource Identifier (RRID): AB_390740 and AB_2230924]. Antibody complexes were detected by Alexa Fluor anti-mouse and anti-rabbit fluorescent-conjugated antibodies (Invitrogen) and visualized using an Odyssey CLx image scanner (Li-Cor Biosciences; Lincoln, NE, USA). Blots were quantified using LI-COR ${ }^{\circledR}$ Image Studio software (version 5.2) and normalized to Revert Total Protein Stain (Li-Cor Biosciences).

\section{Measurement of protein synthesis}

HTR-8/SVneo cells were seeded at a density of 10,000 cells per well in a black clear-bottomed 96-well plate and allowed to acclimate for $24 \mathrm{~h}$. Cells were treated with medium alone (control) or DCVC $(10$ or $20 \mu \mathrm{M})$ for 6 or $12 \mathrm{~h}$. Protein synthesis was measured with a Protein Synthesis Assay Kit (Thermo Fisher Scientific) according to the manufacture's recommended protocols. This assay utilizes cell-permeable
O-propargyl-puromycin (OPP), which halts the translation of polypeptide chains by incorporating into the $\mathrm{C}$-terminus. Briefly, cells were incubated with OPP solution for $2 \mathrm{~h}$ at $37{ }^{\circ} \mathrm{C}$, fixed, and incubated with FAM-Azide solution (FAM-Azide, copper sulfate and ascorbic acid) for $30 \mathrm{~min}$ in the dark at room temperature. After incubation, protein synthesis was measured fluorescently (excitation: $485 \mathrm{~nm}$; emission $535 \mathrm{~nm}$ ) using a SpectraMax M2e Multi-Mode Microplate Reader (Molecular Devices; Sunnyvale, CA, USA).

\section{Statistical analysis for non-RNA sequencing experiments}

Western blotting, protein synthesis measurement, cell cycle determination, and proliferation experiments were performed independently and repeated a minimum of three times. When applicable, technical replicates were averaged within each experiment and these values were analyzed using one-way or two-way analysis of variance (ANOVA) followed by Tukey's post-hoc test for comparison of means. GraphPad Prism software version 7 was used for statistical analysis (GraphPad Software Inc.; San Diego, CA, USA). Data are expressed as means \pm stand error of the means (SEM). $N=$ number of independent experiments. $P<0.05$ was considered statistically significant.

\section{Results}

\section{Effect of DCVC on cellular proliferation and cell cycle progression in HTR-8/SVneo cells}

We evaluated key biological processes as indicators of acute cytotoxicity after exposure to $0-20 \mu \mathrm{M}$ DCVC for up to $12 \mathrm{~h}$ in the HTR-8/SVneo cell line. We previously reported that $12-\mathrm{h} 20 \mu \mathrm{M}$ DCVC treatment did not cause cell death in the same cell line (Elkin et al. 2020b). Here, we extended those findings by showing that the maximal 12-h $20 \mu \mathrm{M}$ DCVC treatment did not cause significant expression changes in genes that regulate apoptosis (Suppl. Table 1). Moreover, there were no significant DCVC-induced changes in cell cycle progression (Suppl Fig. 1), proliferation (Suppl Fig. 2) or the majority of genes that regulate these cellular functions (Suppl. Table 2). These results suggest that the concentrations and time durations used in this study did not cause overt toxicity in the cell model, likely due to biological resilience at these stages. 


\section{Effects of DCVC on placental HTR-8/SVneo gene expression}

In order to evaluate the effects of DCVC on the first trimester placental extravillous trophoblasts, RNA sequencing analyses were performed on HTR-8/SVneo cells to measure differential gene expression between treated cells and controls. Average LogFC of expression levels for comparisons between all treated versus control samples are displayed in a heatmap in Fig. 2. Genes were ordered based on hierarchical clustering. In MDS diagrams depicting all samples plotted on relevant covariates, clustering by treatment duration and replicate were observed (Suppl Fig. 3). The replicate covariate $\left(P=3.84 \times 10^{-04}\right)$ was associated with MDS dimension 1, while treatment duration $\left(P=9.03 \times 10^{-11}\right)$ was associated with MDS dimension 2 .

\section{Concentration-dependent differential gene expression after 6-h DCVC treatment}

Comparison of altered gene expression in cells exposed to 10 versus $20 \mu \mathrm{M}$ DCVC for $6 \mathrm{~h}$ was conducted by calculating pairwise correlation coefficients of $\log F C$ estimates. Differential changes in gene expression relative to control were strongly correlated for cells exposed to $10 \mu \mathrm{M}$ DCVC versus $20 \mu \mathrm{M}$ DCVC after a 6-h treatment $[r=0.51$, $P<1.0 \times 10^{-15}$ ] (Suppl Fig. 4a). Furthermore, for genes that met the FDR criterion for significant differential gene expression $(\mathrm{FDR}<0.05)$ and had a $\log \mathrm{FC}>0.35$ [FC $>1.3$ ], $20 \mu \mathrm{M}$ DCVC treatment-induced larger magnitude altered gene expression compared with $10 \mu \mathrm{M}$ DCVC, indicating a concentration-dependent response (Fig. 3a).

Both 10 and $20 \mu \mathrm{M}$ DCVC treatment in cells for $6 \mathrm{~h}$ caused differential gene expression with some overlap. For example, the only gene that met both criteria $(\mathrm{FDR}<0.05+\log \mathrm{FC}>0.35$ [FC $>1.3]$ ) for significant differential gene expression with $10 \mu \mathrm{M}, 5^{\prime}$-aminolevulinate synthase 1 (ALAS1) $\left(0.37 \log \mathrm{FC}[1.3 \mathrm{FC}], \mathrm{FDR}=2.15 \times 10^{-03}\right)$, was also differentially expressed with $20 \mu \mathrm{M}(0.37 \log \mathrm{FC}$ $\left.[1.3 \mathrm{FC}], \mathrm{FDR}=5.51 \times 10^{-04}\right)($ Fig. $3 \mathrm{~b})$. The $10 \mu \mathrm{M} \mathrm{DCVC}$ treatment group yielded an additional 276 genes that had a $\operatorname{logFC}$ magnitude difference $>0.35$ [FC $>1.3$ ] but did not meet the FDR criterion (Fig. 3c, Suppl. Table 3). Consequently, $10 \mu \mathrm{M}$ treatment for $6 \mathrm{~h}$ demonstrated the smallest transcriptional response out of all the comparisons made for HTR-8/SVneo cells. Whereas $20 \mu \mathrm{M}$ DCVC treatment for $6 \mathrm{~h}$ yielded 7 differentially expressed genes that met FDR $<0.05$ criterion only, an additional 354 genes had a $\log \mathrm{FC}$ magnitude difference $>0.35$ [FC $>1.3$ ] only. Moreover, a total of 12 genes met both criteria (Fig. 3d, Suppl. Table 3). Among the genes that met both criteria, the highest magnitude differentially expressed genes between $20 \mu \mathrm{M}$-treated and controls were oxidative stressinduced growth inhibitor (OSGIN1) (0.91 logFC [1.9 FC], $\mathrm{FDR}=0.036)$, tripartite motif-containing 16-like $($ TRIM16L $)$ $(0.63 \log \mathrm{FC}[1.5 \mathrm{FC}], \mathrm{FDR}=0.036)$ and glutathione-specific gamma-glutamylcyclotransferase 1 (CHACl) $(0.62 \operatorname{logFC}$ [1.5 FC], FDR = 0.015) (Suppl. Table 3). Overall, these results indicate an increase in the number of genes differentially expressed with $20 \mu \mathrm{M}$ DCVC, compared to $10 \mu \mathrm{M}$ treatment.

Genes differentially expressed by 6-h DCVC treatment were also enriched in pathways, as identified by GSEA. Although $6 \mathrm{~h} \mathrm{DCVC}$ treatment yielded no pathways that were upregulated with $10 \mu \mathrm{M}$ DCVC, two pathways were downregulated (Fig. 3e). Treatment with $20 \mu \mathrm{M}$ DCVC upregulated one pathway and downregulated six pathways (Fig. 3f). Of the six downregulated pathways, four

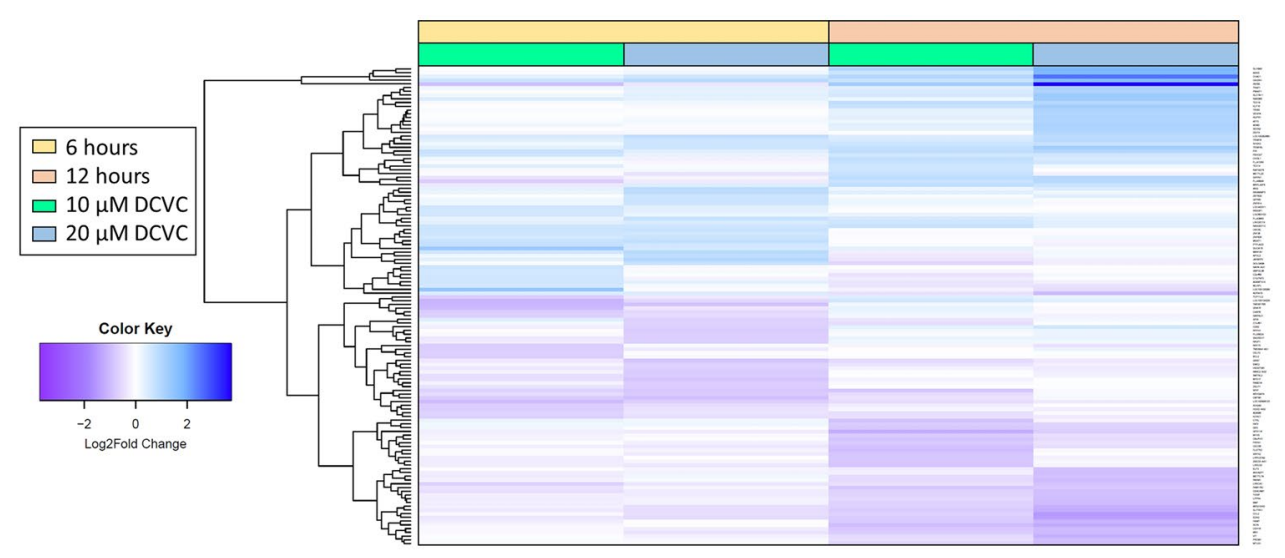

Fig. 2 Top $\log$ FC expression levels for comparisons between treated versus control samples. HTR-8/SVneo cells were treated with 0 (control), 10 or $20 \mu \mathrm{M}$ DCVC for 6 or $12 \mathrm{~h}$. Heatmap depicts expression levels for the 40 genes with the largest magnitude $\operatorname{logFC}$ (up and downregulated) from each of the following comparisons: control vs. $10 \mu \mathrm{M}$ DCVC $(6 \mathrm{~h})$, control vs. $20 \mu \mathrm{M}$ DCVC (6 h), control vs. $10 \mu \mathrm{M}$ DCVC (12 h) and control vs. $20 \mu \mathrm{M} \mathrm{DCVC} \mathrm{(12} \mathrm{h)}$ 
were involved in embryonic development, the most common category. Representative pathways in this category include epithelial-mesenchymal transition $(\mathrm{NES}=-1.97$, $\mathrm{FDR}=0.001)$ and myogenesis $(\mathrm{NES}=-1.79, \mathrm{FDR}=0.004)$. Other categories represented among downregulated pathways included immune response (2) proliferation (1) and cellular organization (1). The overall pattern of pathways affected by DCVC treatment for $6 \mathrm{~h}$ consisted primarily of the downregulation of pathways associated with embryonic development.

\section{Concentration-dependent differential gene expression after $12 \mathrm{~h}$ DCVC treatment}

In order to evaluate patterns in gene expression caused by 12-h DCVC treatment, correlation of expression levels across DCVC treatment concentrations (10 versus $20 \mu \mathrm{M})$, were evaluated. Changes in gene expression levels (relative to control) were strongly correlated for cells exposed to $10 \mu \mathrm{M}$ versus $20 \mu \mathrm{M}$ DCVC after a 12 -h treatment $[r=0.67$, $P<1.0 \times 10^{-15}$ ] (Suppl Fig. 4b). Furthermore, for genes that met the FDR criterion for significant differential gene expression $(\mathrm{FDR}<0.05)$ and had $\log \mathrm{FC}>0.35[\mathrm{FC}>1.3]$, $20 \mu \mathrm{M}$ DCVC treatment-induced larger magnitude altered gene expression compared with $10 \mu \mathrm{M}$ DCVC, further indicating a concentration-dependent response (Fig. 4a).

Similar to 6-h results, both 10 and $20 \mu \mathrm{M}$ DCVC treatment for $12 \mathrm{~h}$ caused significant differential gene expression with substantial overlap. For example, the 15 genes that met both criteria $(\mathrm{FDR}<0.05+\log \mathrm{FC}>0.35[\mathrm{FC}>1.3]$ ) for significant differential gene expression with $10 \mu \mathrm{M}$ DCVC, were also differentially expressed with $20 \mu \mathrm{M}$ (Fig. 4b). Additionally, $10 \mu \mathrm{M}$ DCVC treatment yielded 17 differentially expressed genes that met FDR $<0.05$ criterion only, and 373 genes had a $\log \mathrm{FC}$ magnitude difference $>0.35$ [FC $>1.3$ ] only (Fig. 4c, Suppl. Table 4). Compared to $10 \mu \mathrm{M}, 20 \mu \mathrm{M}$ DCVC treatment increased the number of genes with altered expression, yielding 526 differentially expressed genes that met FDR $<0.05$ criterion only, 436 genes with a $\log F C$ magnitude difference $>0.35[\mathrm{FC}>1.3]$ only, and 301 genes that met both criteria (Fig. 4d, Suppl. Table 4). Among the genes that met both criteria, 113 were upregulated and 188 were downregulated. The three genes with the largest magnitude $\operatorname{logFC}$ included, inhibin subunit beta $(I N H B E)\left(3.71 \operatorname{logFC}[13 \mathrm{FC}], \mathrm{FDR}=3.00 \times 10^{-04}\right)$, CHAC1 $\left(2.55 \operatorname{logFC}\left[5.9 \mathrm{FC}\right.\right.$ ], FDR $\left.=1.25 \times 10^{-09}\right)$ and sodium- and chloride-dependent glycine transporter 1 $\left(\right.$ SLC6A9) $\left(1.81 \log\right.$ FC [3.0 FC], FDR $\left.=5.46 \times 10^{-04}\right)$ (Suppl. Table 4). Although more downregulated genes met both FDR and $\log \mathrm{FC}$ criteria, the upregulated genes had larger magnitude differential gene expression.

Multiple enriched biological and molecular signaling pathways connected to differential gene expression were upregulated by 12 -h DCVC treatment. Ten micromolar treatment upregulated 2 pathways (Fig. 4e). Twenty micromolar treatments upregulated 9 pathways, 5 of which were involved in response to stress stimuli (Fig. 4f). Representative pathways included unfolded protein response (NES $=2.36$, FDR $>0.001)$ and mTORC1 signaling (NES $=2.16$, FDR $>0.001)$. Moreover, $12-79 \%$ of individual genes enriched within each of these pathway gene sets were targets of the ATF4 gene, which codes for a key transcription factor associated with ISR, a branch of the UPR. (Suppl. Table 6). In addition to the response to stress stimuli, upregulated pathways also involve metabolic processes (4), immune processes (2) and proliferation (1).

Likewise, DCVC treatment for $12 \mathrm{~h}$ downregulated numerous biological and molecular signaling pathways. With $10 \mu \mathrm{M}$ DCVC, 6 pathways were downregulated, half of which were associated with the most common category, embryonic development (Fig. 4e). Twenty micromolar DCVC treatment downregulated 13 pathways (Fig. 4f). Similar to $10 \mu \mathrm{M}$ DCVC, the majority of these pathways (7) were associated with embryonic development. Representative pathways included epithelial-mesenchymal transition $(\mathrm{NES}=-2.12, \mathrm{FDR}<0.001)$, myogenesis $(\mathrm{NES}=-1.66$, $\mathrm{FDR}=0.021)$ and hedgehog signaling $(\mathrm{NES}=-1.61$, Other categories represented among the pathways downregulated with 12-h $20 \mu \mathrm{M}$ DCVC treatment included proliferation (3), cellular organization (2) and response to stress stimuli (2). Summarizing the overall pattern of pathways affected by DCVC treatment, pathways involved in cellular response to stress stimuli were upregulated and pathways related to embryonic development were downregulated.

\section{Time-dependent differential gene expression after 10 or $20 \mu \mathrm{M}$ DCVC treatment}

In addition to concentration-dependent DCVC effects, altered gene expression associated with treatment duration was investigated. Comparison of gene expression changes in cells exposed for 6 versus $12 \mu \mathrm{M}$ DCVC was evaluated by calculating pairwise correlation coefficients of $\log \mathrm{FC}$ estimates. The overall differential gene expression levels (relative to control) were moderately correlated by time for both $10 \mu \mathrm{M}$ DCVC treatment $[r=0.14$, $P<1.0 \times 10^{-15}$ ] (Suppl Fig. 5a) and $20 \mu \mathrm{M}$ DCVC treatment $\left[r=0.24, P<1.0 \times 10^{-15}\right.$ ] (Suppl Fig. 5b). Moreover, differentially expressed genes with a $\log \mathrm{FC}>0.35$ [FC $>1.3]$ and FDR $<0.05$ after 12-h treatment, had larger expression changes than 6-h treatment, indicating time-dependent responses for both concentrations tested (Fig. 5a, c). For $10 \mu \mathrm{M}$ treatment, the only gene significantly differentially expressed (FDR $<0.05+\log \mathrm{FC}>0.35[\mathrm{FC}>1.3]$ ) with 6-h DCVC treatment, $A L A S 1$, was also differentially expressed with 12-h treatment along with 14 additional genes (Fig. 5b). 

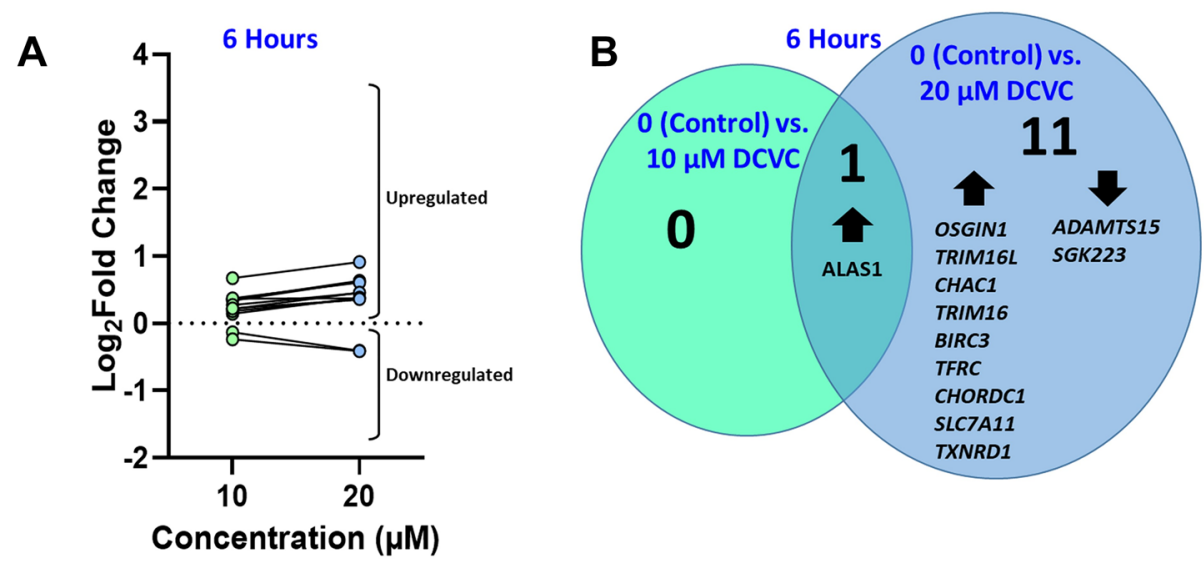

C

HTR-8/SVneo: 0 (Control) vs. $10 \mu \mathrm{M}$ DCVC

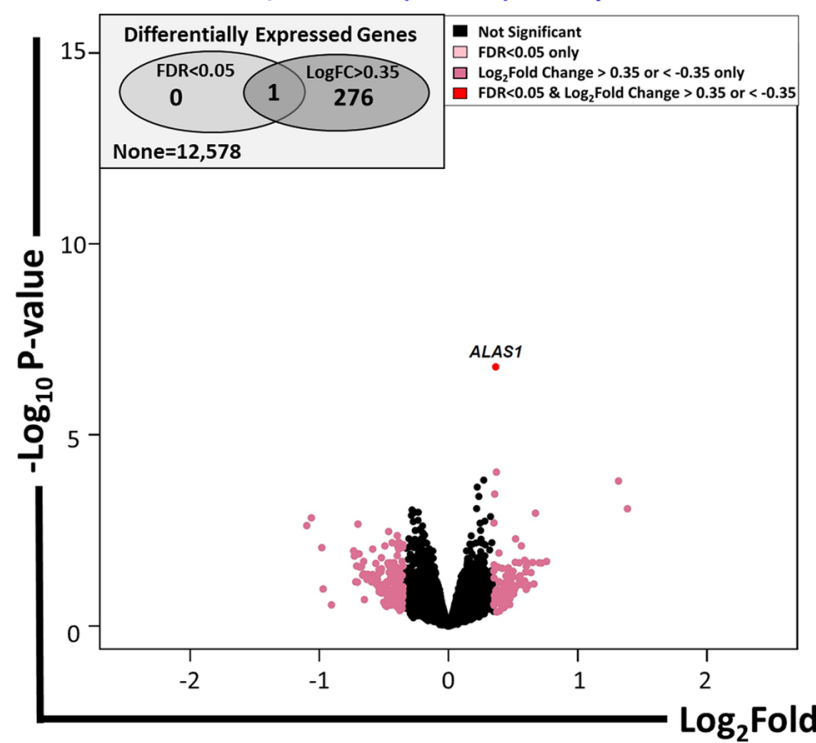

D

HTR-8/SVneo: 0 (Control) vs. $20 \mu$ M DCVC
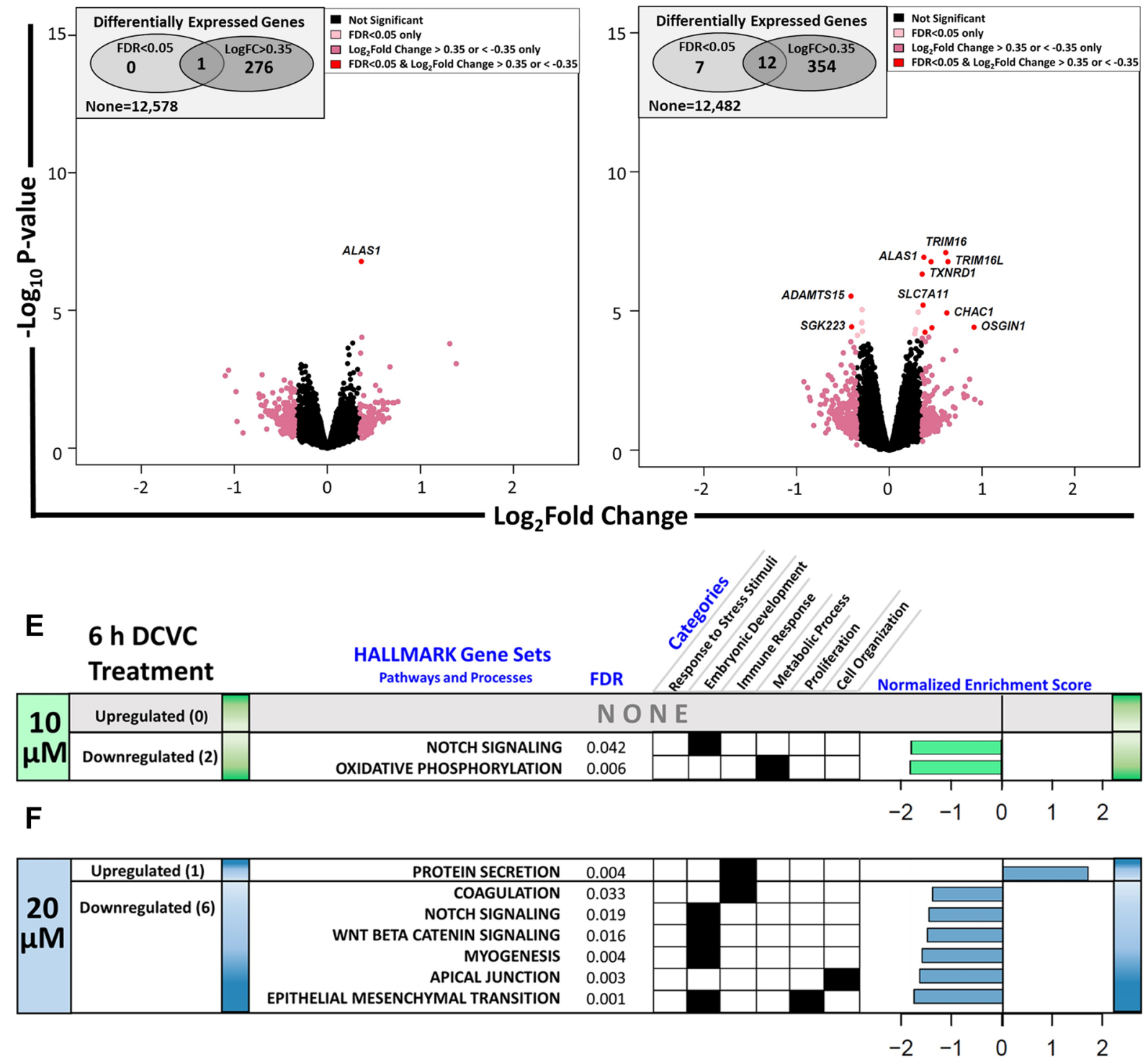
4Fig. 3 Effects of 6-h DCVC treatment on HTR-8/SVneo gene expression. HTR-8/SVneo cells were treated with 0 (control), 10 or $20 \mu \mathrm{M}$ DCVC for $6 \mathrm{~h}$. Differential gene expression was analyzed with the edgeR package for $\mathrm{R}$ using quasi-likelihood general linear modeling. $N=4$ independent experiments. a Spaghetti plot depicting concentration-dependent expression levels for genes meeting FDR and $\log \mathrm{FC}$ criteria. Blue dots represent individual genes differentially expressed $(\mathrm{FDR}<0.05+\log \mathrm{FC}>0.35[\mathrm{FC}>1.3])$ with $20 \mu \mathrm{M}$ DCVC. Lines connecting blue dots to green dots represent the same respective genes with $10 \mu \mathrm{M}$ expression levels. b Venn diagram depicting overlap in differentially expressed genes (FDR $<0.05+\operatorname{logFC}>0.35$ [FC>1.3]) at $6 \mathrm{~h}$, between 0 (control) vs. $10 \mu \mathrm{M}$ and 0 vs. $20 \mu \mathrm{M}$ DCVC. Volcano plots comparing differential gene expression between non-treated (controls) cells and 6-h DCVC-treated cells are depicted for: c $10 \mu \mathrm{M}$ DCVC and d $20 \mu \mathrm{M}$ DCVC. Genes were considered differentially expressed with FDR $<0.05$. Genes fulfilling the following criteria are denoted by color: FDR $<0.05$ only (light pink), $\log \mathrm{FC}$ magnitude $>0.35$ [FC $>1.3]$ only (dark pink), and FDR $<0.05+\log F C$ magnitude $>0.35$ [FC $>1.3$ ] (red). Upregulated and downregulated gene sets from the MSigDB hallmark collection were identified through GSEA as enriched after treatment with e $10 \mu \mathrm{M}$ DCVC or $\mathbf{f} 20 \mu \mathrm{M}$ DCVC. Relevant characteristics of enriched gene sets are reported as: FDR, biological pathway categories and normalized enrichment score (NES). Gene sets are ordered according to magnitude of NES and were considered enriched with an FDR $<0.05$

Likewise, among the 12 genes differentially expressed after 6-h $20 \mu \mathrm{M}$ DCVC treatment, 10 genes were also differentially expressed after 12 -h $20 \mu \mathrm{M}$ treatment (Fig. 5d). Moreover, there were 2 genes exclusively differentially expressed with 6-h $20 \mu \mathrm{M}$ treatment and 289 genes with 12-h $20 \mu \mathrm{M}$ treatment.

Time-dependent differential gene expression was further investigated by evaluating temporal patterns in the regulation of gene expression. When grouped by chronological expression patterns, the majority of genes with a logFC magnitude $>0.35$ [FC $>1.3$ ], fit into one of the four different groups consisting of early and late responders: that is, differential expression (up or downregulated) at one time point and unchanged expression at the other time point. Each of these groups contained $>100$ genes (Fig. 6). These results indicate a pattern of nonlinearity in gene expression over time. Furthermore, the no change $\rightarrow$ upregulated groups were enriched for the ATF4 transcription factor for both $10 \mu \mathrm{M}$ (enriched odds ratio: $26, \mathrm{FDR}=6.51 \times 10^{-4}$ ) and $20 \mu \mathrm{M}$ DCVC (enriched odds ratio: $23, \mathrm{FDR}=2.84 \times 10^{-5}$ ). Additionally, the no change $\rightarrow$ downregulated group for $20 \mu \mathrm{M}$ was enriched for two transcription factors and one histone modification that regulate gene expression during embryonic development: transcription factors PAX6 (enriched odds ratio: $8, \mathrm{FDR}=1.28 \times 10^{-2}$ ) and SMAD3 (enriched odds ratio: $7, \mathrm{FDR}=1.54 \times 10^{-2}$ ), and histone tri-methylation site $\mathrm{H} 3 \mathrm{~K} 27 \mathrm{me} 3$ (enriched odds ratio: 23, FDR $=1.18 \times 10^{-10}$ ). The other 4 groups consisting of temporary and consistent responders-genes with expression $\log \mathrm{FC}$ magnitude $>0.35$ [FC $>1.3$ ], at both 6 and $12 \mathrm{~h}$ (up and/or down-regulated)_each contained $<50$ genes with no enrichment for specific regulation of gene expression (Fig. 6).

\section{DCVC effect on ISR-associated ATF4 regulation of gene expression in cells}

Because ATF4-driven transcriptional activity is a key indicator of UPR/ISR activation, ATF4 gene targets, previously determined elsewhere (Bao et al. 2016; Han et al. 2013; Quiros et al. 2017; Shpilka and Haynes 2018), were tested for overrepresentation among DCVC-induced differentially expressed genes using a statistical enrichment test. Of the 301 differentially expressed genes $(\mathrm{FDR}<0.05+\log \mathrm{FC}>0.35[\mathrm{FC}>1.3])$ resulting from exposure to $20 \mu \mathrm{M}$ DCVC for $12 \mathrm{~h}, 15.6 \%$ (47 genes) were identified as ATF4 gene targets, reflecting a statistically significant overrepresentation (Fig. $7 \mathrm{a}, P=5.52 \times 10^{-22}$ ). Of the 47 ATF4 gene targets, 44 were upregulated and 3 were downregulated (Fig. 7b, FDR $<0.05+\log$ FC $>0.35$ [FC $>1.3])$. These results support ISR activation as a major response in HTR-8/SVneo cells to DCVC exposure.

To further characterize the specific roles of individual ATF4 gene targets during ISR activation, the ATF4 gene plus the 47 ATF4-regulated genes with an FDR $<0.05$ and magnitude $\log \mathrm{FC}>0.35$ [FC $>1.3$ ] (up or down) were grouped by function with single gene-level $\log F C$ displayed (Fig. 7c). Most of the ATF4-regulated genes are involved in various biological processes necessary for cellular compensation to DCVC-induced stress. Notably, 5 amino acid transporter genes were significantly differentially expressed: SLC1A4, SLC1A5, SLC6A9, and SLC7A11 $(\mathrm{FDR}<0.05+\log \mathrm{FC}>0.35$ [FC $>1.3])$ (Fig. 7c). Contrarily, some of the ATF4-regulated genes control biological processes that contribute to cell death. Moreover, many of these genes are co-regulated by dimerization with $\mathrm{C} / \mathrm{EBP}$ homologous protein (CHOP), another transcription factor which is itself regulated by ATF4 (Han et al. 2013; Hu et al. 2018; Su and Kilberg 2008). Particularly, 9 amino acid biosynthesis genes were differentially expressed at a significant level: AARS, ASNS, CARS, GARS, MARS, SARS, TARS and YARS (FDR $<0.05+\log \mathrm{FC}>0.35$ [FC $>1.3]$ ) (Fig. 7c). These findings suggest complex ISR signaling in the cells involving both compensation and cell death.

\section{Validation of DCVC-induced integrated stress response in HTR-8/SVneo cells}

\section{elF2a phosphorylation and ATF4 protein levels}

Because the majority of gene sets positively enriched by 12-h exposure to DCVC contained substantial core enrichment of ISR-associated genes in HTR-8/SVneo cells, we 

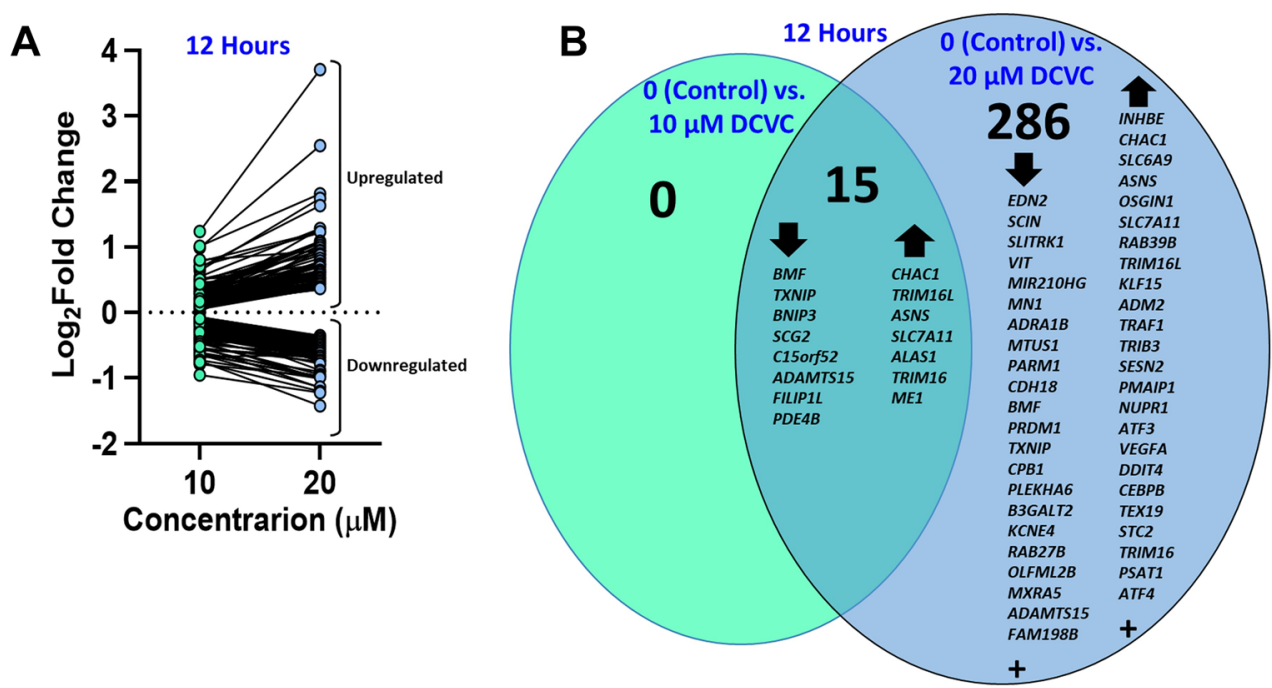

C

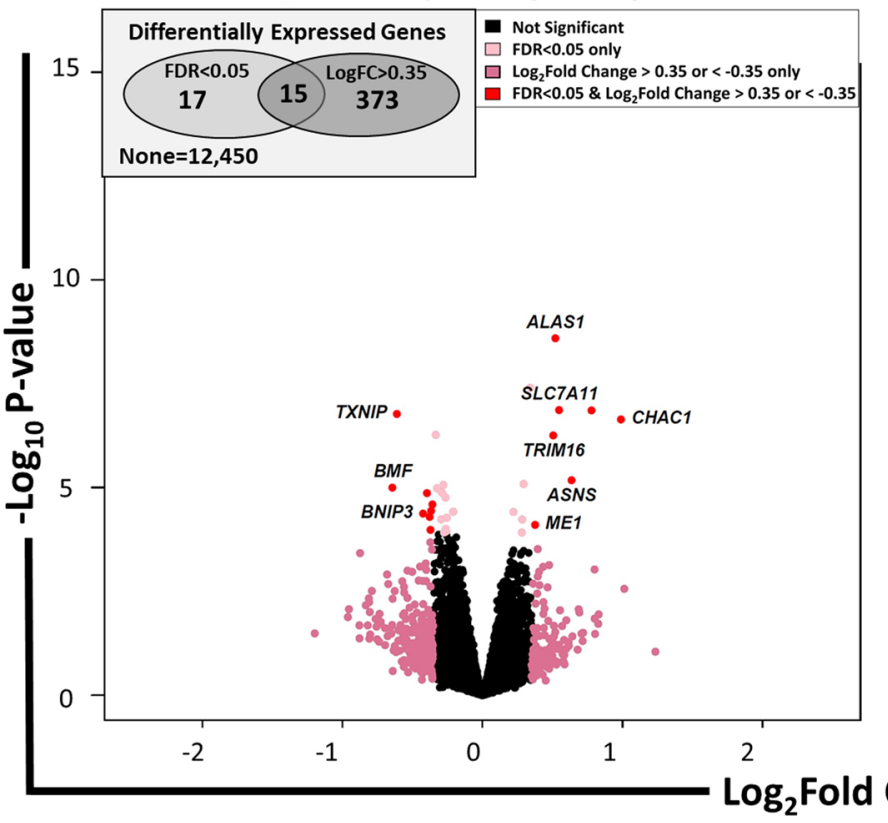

D

HTR-8/SVneo: 0 (Control) vs. $20 \mu \mathrm{M}$ DCVC

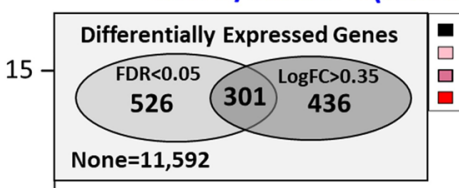

- Not Significant $\square$ FDR $<0.05$ only

L Log $_{2}$ Fold Change $>0.35$ or $<-0.35$ only FDR $<0.05$ \& Log $_{2}$ Fold Change $>0.35$ or $<-0.35$ SLCTA11 CHAC1
ASNS ASNS
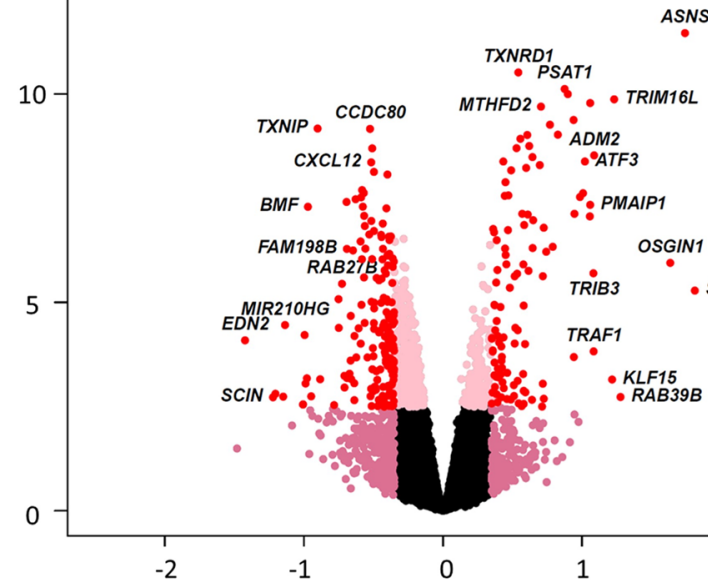
(n)
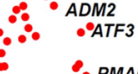

: PMAIP1

OSGIN1

$\because$ TRIB3 • SLC6A9

TRAF1

RAF

$\because$ KLF15
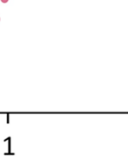

\section{$\log _{2}$ Fold Change}

Fig. 4 Effects of 12-h DCVC treatment on HTR-8/SVneo gene expression. HTR-8/SVneo cells were treated with 0 (control), 10 or $20 \mu \mathrm{M}$ DCVC for $12 \mathrm{~h}$. Differential gene expression was analyzed with the edge $\mathrm{R}$ package for $\mathrm{R}$ using quasi-likelihood general linear modeling. $N=4$ independent experiments. a Spaghetti plot depicting concentration-dependent expression levels for genes meeting FDR and $\log F C$ criteria. Blue dots represent individual genes differentially expressed (FDR $<0.05+\log \mathrm{FC}>0.35$ [FC $>1.3]$ ) with $20 \mu \mathrm{M}$ treatment. Lines connecting blue dots to green dots represent the same respective genes with $10 \mu \mathrm{M}$ expression levels. b Venn diagram depicting overlap in differentially expressed genes $(\mathrm{FDR}<0.05+\log \mathrm{FC}>0.35[\mathrm{FC}>1.3])$ at $12 \mathrm{~h}$, between 0 (control) vs. $10 \mu \mathrm{M}$ and 0 vs. $20 \mu \mathrm{M}$ DCVC. Volcano plots comparing differential gene expression between non-treated (controls) cells and 12-h DCVC-treated cells are depicted for: c $10 \mu \mathrm{M}$ DCVC and d $20 \mu \mathrm{M}$ DCVC. Genes were considered differentially expressed with FDR $<0.05$. Genes fulfilling the following criteria are denoted by color: FDR $<0.05$ only (light pink), logFC magnitude $>0.35$ [FC $>1.3$ ] only (dark pink), and FDR $<0.05+\log \mathrm{FC}$ magnitude $>0.35[\mathrm{FC}>1.3]$ (red). Upregulated and downregulated gene sets from the MSigDB hallmark collection were identified through GSEA as enriched after treatment with e $10 \mu \mathrm{M}$ DCVC or $\mathbf{f} 20 \mu \mathrm{M}$ DCVC. Relevant characteristics of enriched gene sets are reported as FDR, pathway categories and normalized enrichment score (NES). Gene sets are ordered according to magnitude of NES and were considered enriched with an FDR $<0.05$. Gene sets with an asterisk indicate they that the pathways contained ISR/ATF4-regulated enriched genes (detailed information found in suppl. table 6) 
E

$12 \mathrm{~h}$ DCVC Treatment

HALLMARK Gene Sets

Pathways and Processes

\begin{tabular}{|c|c|c|}
\hline & Upregulated (2) & $\begin{array}{r}\text { OXIDATIVE PHOSPHORYLATION } \\
\text { UNFOLDED PROTEIN RESPONSE* }\end{array}$ \\
\hline $\begin{array}{c}10 \\
\mu M\end{array}$ & Downregulated (6) & $\begin{array}{r}\text { KRAS SIGNALING DOWN } \\
\text { MYOGENESIS } \\
\text { UV RESPONSE DOWN } \\
\text { HEDGEHOG SIGNALING } \\
\text { HYPOXIA } \\
\text { EPITHELIAL MESENCHYMAL TRANSITION }\end{array}$ \\
\hline
\end{tabular}

$\mathbf{F}$

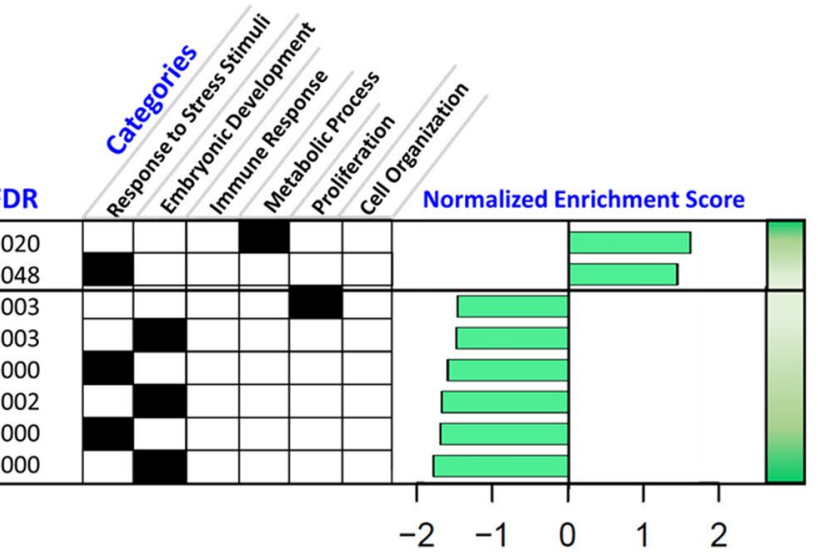

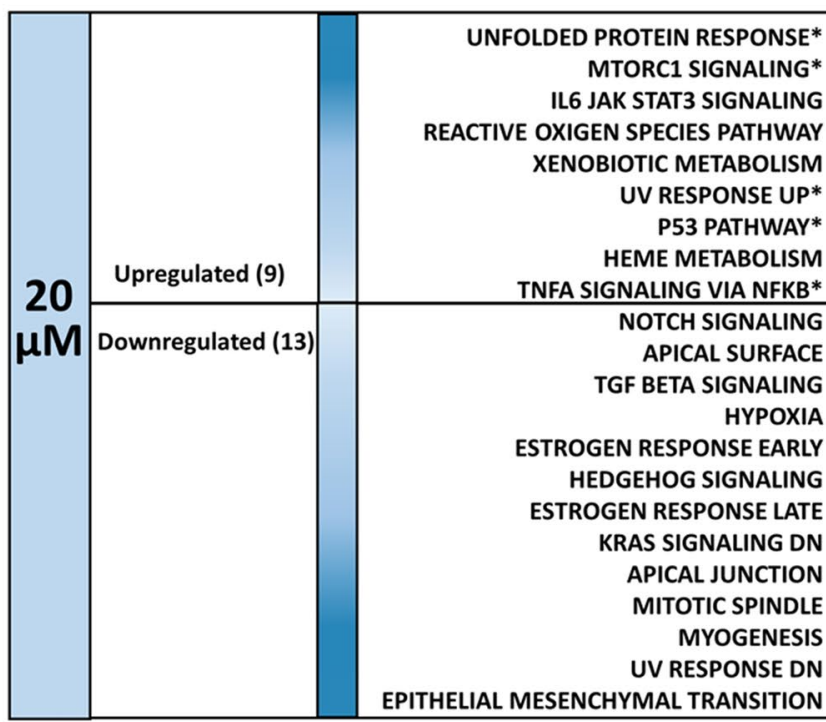

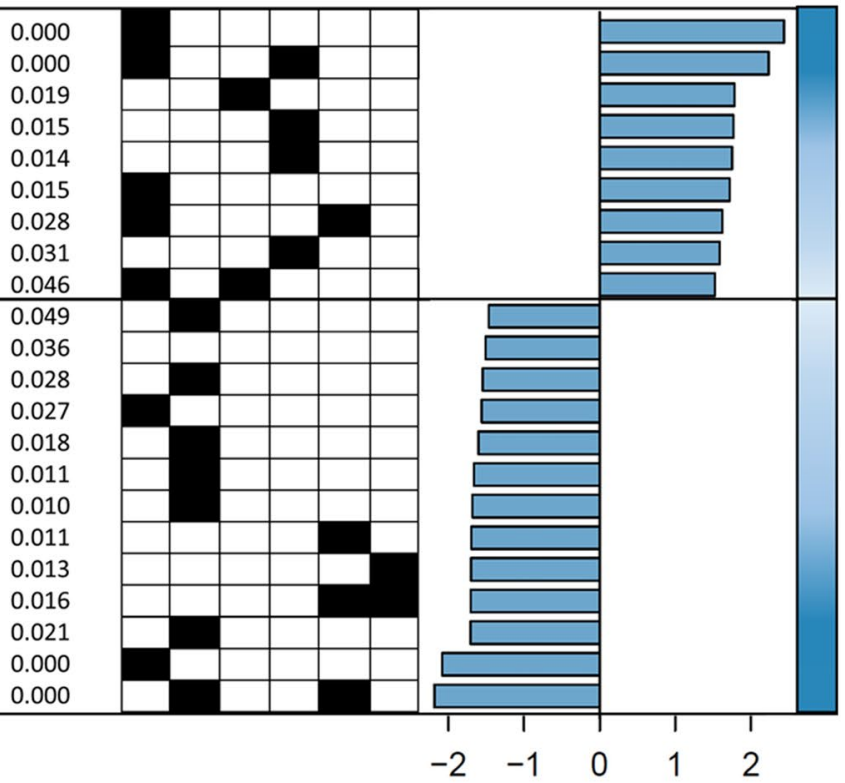

Fig. 4 (continued)

verified DCVC-induced ISR activation in cells using western blot analysis to measure phosphorylation levels of eIF $2 \alpha$ and protein concentrations of ATF4, key regulators of ISR activation (Fig. $8, P<0.05$ ). Exposure to $20 \mu \mathrm{M} \mathrm{DCVC}$ for $12 \mathrm{~h}$ increased the ratio of phosphorylated to non-phosphorylated eIF $2 \alpha$ protein by $61 \%$ compared to non-treated controls (Fig. 8a, $P=0.031$ ), indicating ISR activation. Furthermore, DCVC increased ATF4 protein concentrations by more than fourfold compared to controls (Fig. 8b, $P=0.027$ ), consistent with activation of the ISR.

\section{DCVC effect on global protein synthesis}

We measured global protein synthesis attenuation, a principal functional feature of ISR signaling through phosphorylation of eIF2 $\alpha$. Although protein synthesis was not significantly altered after a 6-h exposure to DCVC, treatment with $20 \mu \mathrm{M}$ DCVC for $12 \mathrm{~h}$ significantly attenuated protein synthesis $37 \%$ compared with controls (Fig. 9, $P=0.0003$ ). The effect of 12 -h treatment with $10 \mu \mathrm{M}$ DCVC was not statistically significant compared with controls.

\section{Effects of DCVC on placental villous explant gene expression}

To further characterize the effects of DCVC treatment on differential gene expression in placenta, RNA sequencing analysis was performed on another first trimester in vitro model, villous explants-a model that retains the native cells and tissue structure of the villi functional unit (Fig. 10; Suppl. Table 5). In MDS diagrams depicting samples plotted on relevant covariates, clustering by donor placenta, sex, and gestational week were observed (Suppl Fig. 6). Gestational week $\left(P=4.00 \times 10^{-4}\right)$ and placental donor $\left(P=5.00 \times 10^{-4}\right)$ 
Fig. 5 Time-dependent differential gene expression after DCVC treatment in HTR-8 SVneo cells. Comparison of differential gene expression across DCVC treatment durations (6 versus $12 \mathrm{~h}$ ) was evaluating by calculating pairwise correlation coefficients of $\log \mathrm{FC}$ estimates $\left(P<1.0 \times 10^{-15}\right)$. Spaghetti plot depicting time-dependent expression levels for differential expressed genes meeting FDR and $\log \mathrm{FC}$ criteria $(\mathrm{FDR}<0.05+\log \mathrm{FC}>0.35$ [FC $>1.3]$ ) for a $10 \mu \mathrm{M} \mathrm{DCVC}$ and C) $20 \mu \mathrm{M}$ DCVC treatment. Tan dots represent individual genes differentially expressed $(\mathrm{FDR}<0.05+\log \mathrm{FC}>0.35$ [FC $>1.3]$ ) with 12-h treatment. Lines connecting yellow dots to tan dots represent the same respective genes with 6-h expression levels. Venn diagrams depicting overlap in differentially expressed genes $(\mathrm{FDR}<0.05+\log \mathrm{FC}>0.35[\mathrm{~F}$ $\mathrm{C}>1.3]$ ) between 6 and $12 \mathrm{~h}$ DCVC treatment for: b 0 (control) vs. $10 \mu \mathrm{M}$ DCVC and d 0 (control) vs. $20 \mu \mathrm{M}$ DCVC

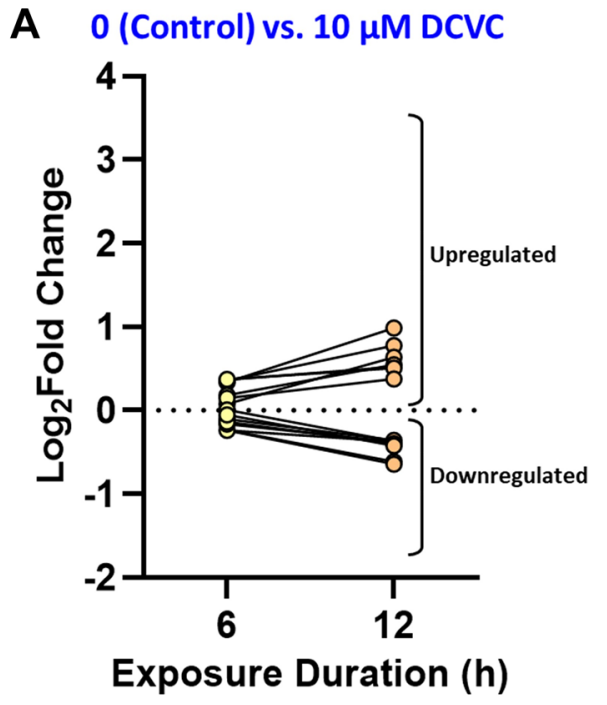

B $\quad 0$ (Control) vs. $10 \mu \mathrm{M}$ DCVC

C 0 (Control) vs. $20 \mu \mathrm{M} \mathrm{DCVC}$

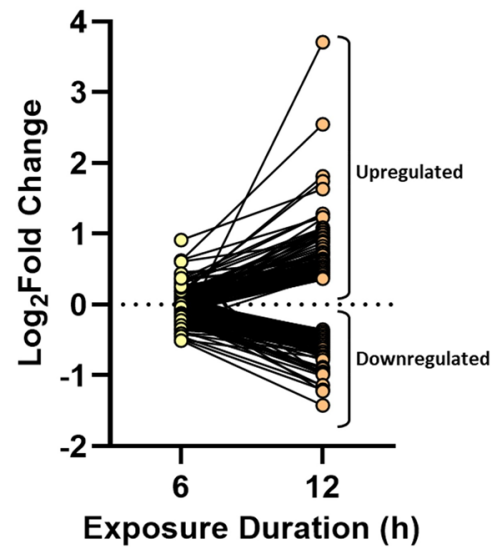

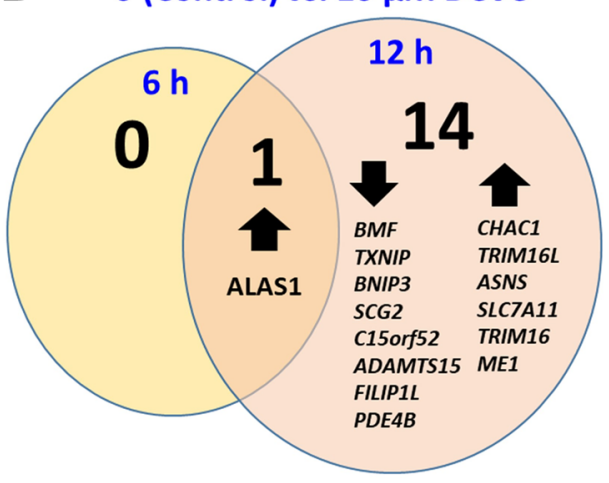

D 0 (Control) vs. $20 \mu \mathrm{M} \mathrm{DCVC}$

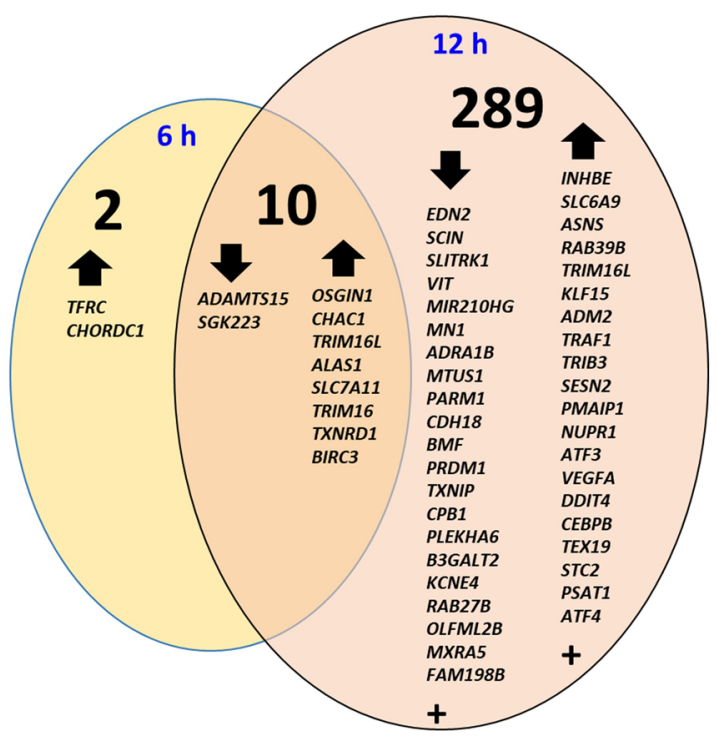

were associated with MDS dimension 1 . Gestational week $\left(P=4.00 \times 10^{-4}\right)$, and placental donor $\left(P=5.00 \times 10^{-4}\right)$ were associated with MDS dimension 2. Twelve-hour $20 \mu \mathrm{M}$ DCVC treatment altered gene expression levels in villous explants by a magnitude $\log \mathrm{FC}>0.35[\mathrm{FC}<1.3]$ for 2684 genes, compared to non-treated controls (Fig. 10a). Among these genes, 1499 were upregulated and 1185 downregulated. Although differential expression for many genes surpassed the $\log \mathrm{FC}$ criterion, as indicated, no genes met the primary false discovery rate criterion (FDR $<0.05)$.

Despite no gene-specific expression levels meeting the FDR criterion, gene set enrichment analysis identified enriched biological and molecular signaling pathways (FDR $<0.05)$. Five pathways were upregulated and each of these involves a cellular response to stress stimuli (Fig. 10b, FDR < 0.05). Representative pathways included:
TNF $\alpha$ signaling via NFKB (NES $=2.60$, FDR $<0.0001)$, p53 pathway $(\mathrm{NES}=1.93, \mathrm{FDR}=0.002)$ and unfolded protein response $(\mathrm{NES}=1.91, \mathrm{FDR}=0.002)$. Furthermore, similar to HTR-8/SVneo cells, 8-31\% of individual genes enriched within each pathway gene set are specifically regulated by ATF4 (Suppl. Table 6). Despite the lack of significant differential expression for individual genes (FDR $<0.05)$, these results reflect a collective transcriptional response to DCVC exposure.

\section{Relationship between placental villous explants and HTR-8/ SVneo ATF4-regulated differential gene expression}

In addition to conducting separate evaluations of DCVCinduced differential gene expression in HTR-8/SVneo cells and explants, a comparison of altered gene expression 

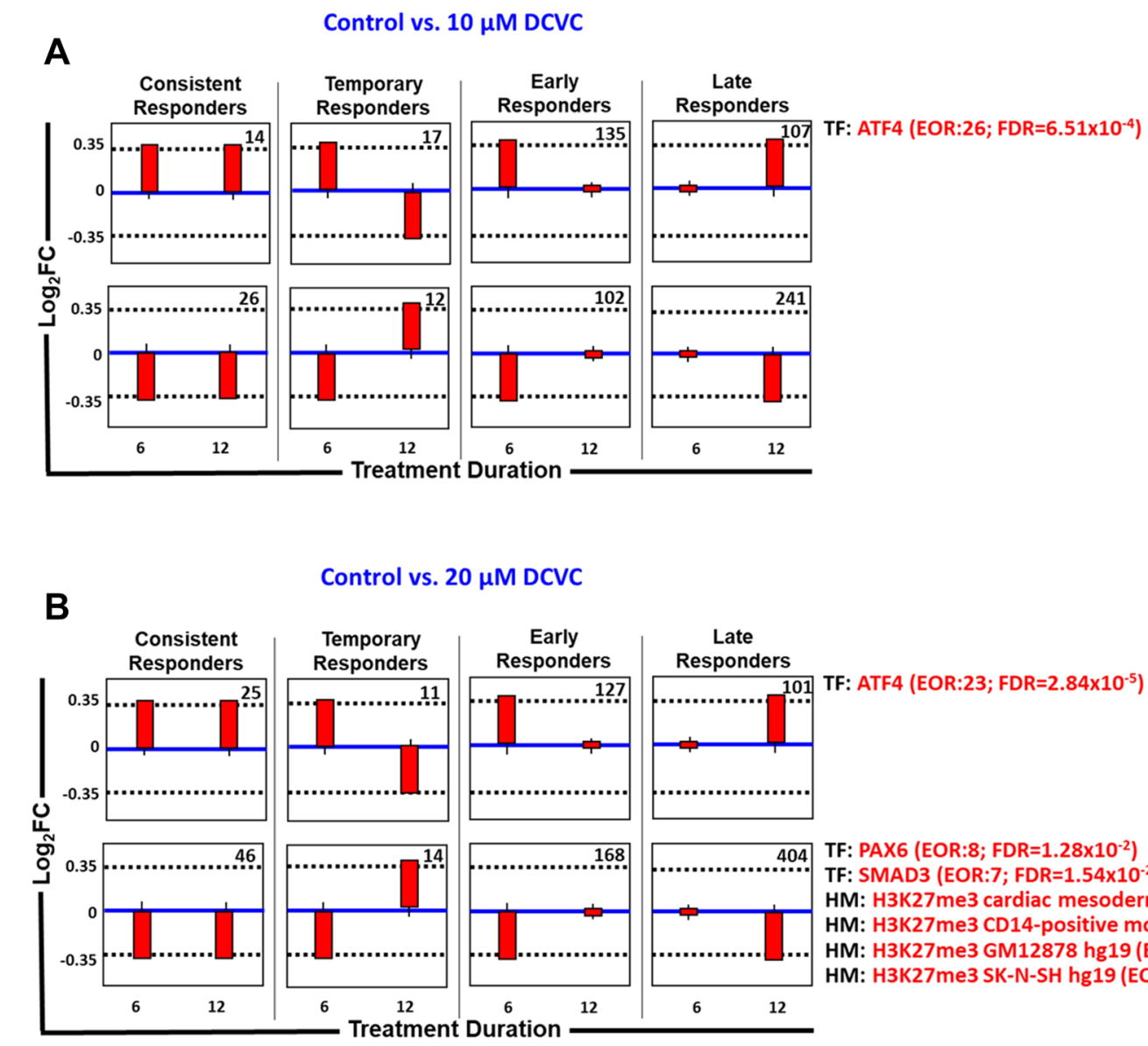

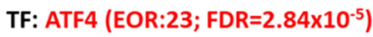
Fig. 6 Temporal patterns in regulation of gene expression in HTR-8/
SVneo cells. Differentially expressed genes with logFC magnitude $>0.35$ [FC $>1.3$ ], regardless of FDR, were grouped together by treatment based on chronological expression patterns (upregulation, downregulated or no change) for the two treatment durations (6 and $12 \mathrm{~h}$ ). There were a total of 8 groups for: a $10 \mu \mathrm{M}$ DCVC and b $20 \mu \mathrm{M}$ DCVC consistent responders (up $\rightarrow$ up and down $\rightarrow$ down),

across the two models was evaluated by calculating pairwise correlation coefficients of $\log F C$ estimates. Differential expression for all dually expressed genes between cells and tissues was correlated $\left[r=0.18, P<1.0 \times 10^{-15}\right.$ (Fig. 11a). A separate pairwise comparison of $\log \mathrm{FC}$ values for the 383 ATF4-regulated genes targets in HTR-8/ SVneo cells versus explants further revealed that the two models were more strongly correlated with ATF4-regulated gene expression $\left[r=0.32, P<1.2 \times 10^{-9}\right]$ (Fig. 11b), than all genes. These results support ISR activation in both models. temporary responders (up $\rightarrow$ down, and down $\rightarrow$ up), early responders (down $\rightarrow$ no change and up $\rightarrow$ no change), and late responders (no change $\rightarrow$ up and no change $\rightarrow$ down). Groups that contained $>100$ genes were tested for enrichment on the Enrichr platform for transcription factors (TF) and histone modifications (HM). The enrichment odds ratio is abbreviated EOR. TF and HM were considered to be significantly enriched with an FDR $<0.05$

\section{Discussion}

\section{Concentration- and time-dependent DCVC effects in HTR-8/SVneo}

In the current study, the HTR-8/SVneo cell line was used the evaluate DCVC concentration- and time-dependent effects on gene expression patterns in placental cells. Both 6-h and 12-h differentially expressed genes demonstrated larger magnitude altered gene expression with $20 \mu \mathrm{M}$ DCVC treatment compared to $10 \mu \mathrm{M}$, indicating a concentration-dependent response. Likewise, genes differentially 
A
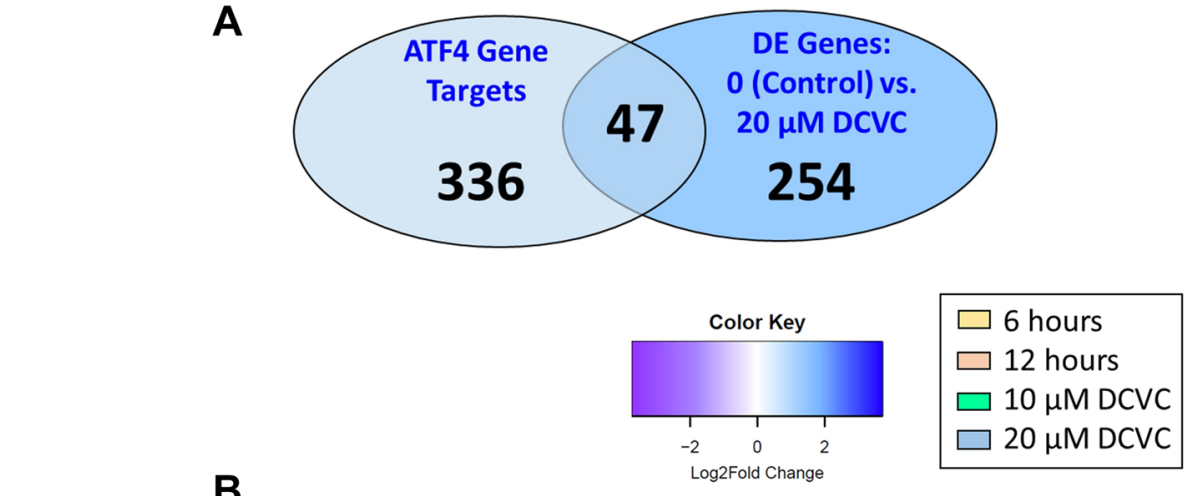

B

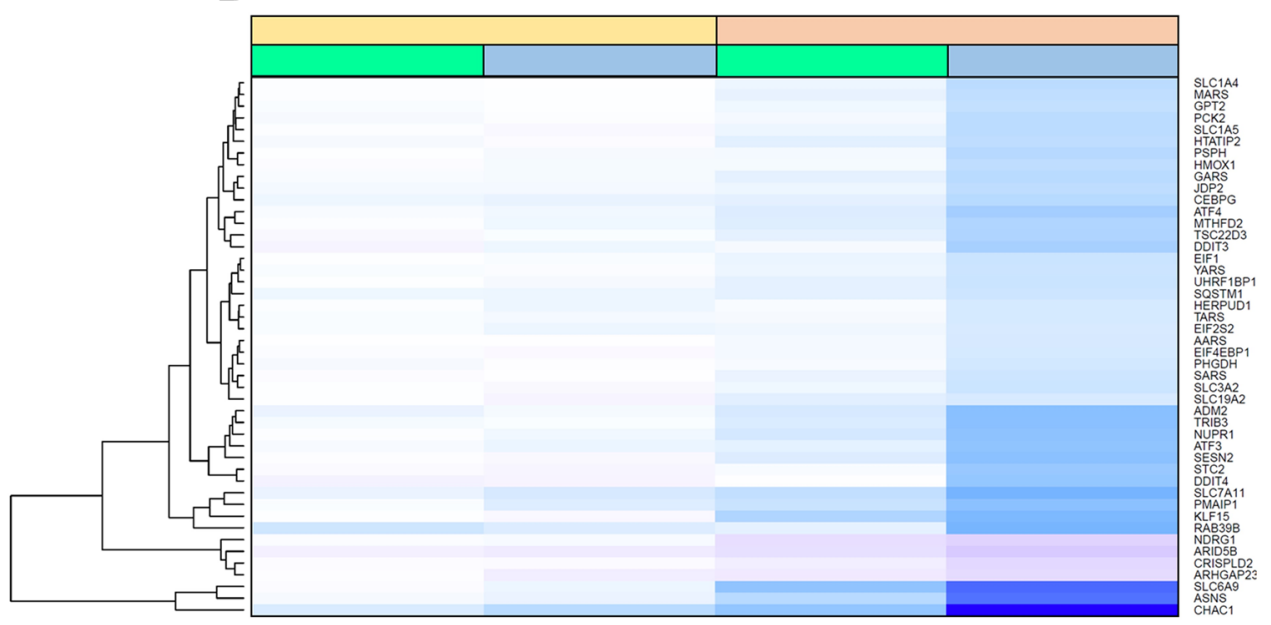

Fig. 7 DCVC effect on ISR-associated ATF4 regulation of gene expression in HTR-8/SVneo cells. Because ATF4 transcriptional regulation is a key regulator of the ISR, ATF4 gene targets were tested for overrepresentation among DCVC-induced differentially expressed genes using a statistical enrichment test. a Venn diagram depicting overlap between the number of ATF4 gene targets and genes differentially expressed (FDR $<0.05+\log \mathrm{FC}>0.35[\mathrm{FC}>1.3]$ ) after a 12-h exposure to $20 \mu \mathrm{M}$ DCVC compared with control $\left(P=5.52 \times 10^{-22}\right)$. b Heatmap visualizing hierarchical clustering and $\log \mathrm{FC}$ expression

expressed by $10 \mu \mathrm{M}$ and $20 \mu \mathrm{M}$ DCVC had larger expression changes with $12-\mathrm{h}$, compared to $6-\mathrm{h}$, indicating a time-dependent response. These results are consistent with several of our previous studies that demonstrated DCVC time- and concentration-dependent effects on mitochondrial dysfunction (Elkin et al. 2019) and molecular apoptotic signaling (Elkin et al. 2018).

\section{DCVC-induced upregulation of the integrated stress response}

In agreement with overall concentration- and time-dependent effects, the upregulated UPR pathway was enriched with $10 \mu \mathrm{M}$ and $20 \mu \mathrm{M}$ DCVC treatment. Moreover, evaluation of temporal patterns revealed that the groups of late responder genes upregulated by $10 \mu \mathrm{M}$ and $20 \mu \mathrm{M}$ DCVC were enriched for the ATF4 transcription factor, specifically of 47 genes differentially expressed (FDR $<0.05+\log \mathrm{FC}>0.35[\mathrm{FC}$ $>1.3]$ ), after exposure to $20 \mu \mathrm{M}$ DCVC for $12 \mathrm{~h}$. Expression levels of other comparisons were included for reference purposes. c Visualization of ATF4 expression, along with the same 47 significantly expressed ATF4 and ATF4 + CHOP gene targets grouped by function and cell fate, with single gene-level $\log \mathrm{FC}$ displayed. Genes displayed in blue are regulated by ATF4 alone, whereas genes displayed in salmon are co-regulated by ATF4 and CHOP

indicating activation of the ISR. When ISR activation is triggered at the cellular level by stress stimuli, including the PERK branch of the UPR, the principal initiating event is the phosphorylation of the translation initiation factor eIF2 $\alpha$ (Pakos-Zebrucka et al. 2016). Furthermore, in order for cellular recovery to occur from stress-induced homeostatic perturbations, eIF $2 \alpha$ phosphorylation concomitantly suppresses global CAP-dependent protein translation while allowing for transcription and translation of selected stress response genes with open read frames in their promotors; namely the central ISR regulatory transcription factor ATF4 (Pakos-Zebrucka et al. 2016; Walter and Ron 2011; Wortel et al. 2017). Indeed, further verification of ISR activation in HTR-8/SVneo cells-beyond differential gene expressiondemonstrated DCVC-induced increased eIF2 $\alpha$ phosphorylation, global attenuation of protein synthesis, and elevation 

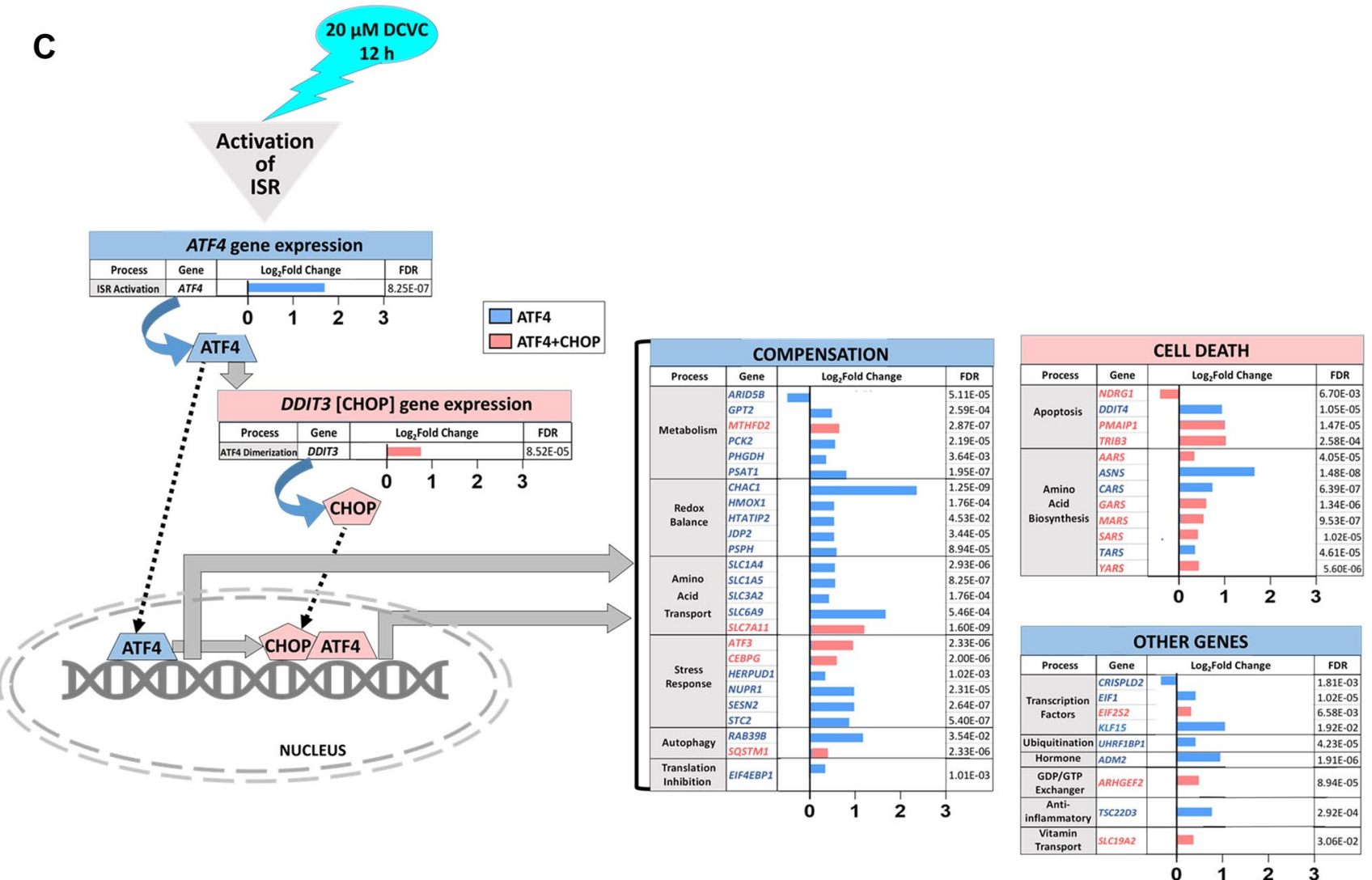

Fig. 7 (continued)

Fig. 8 DCVC effect on principle proteins involved in ISR activation. HTR-8/SVneo cells were treated with 0 (control) or $20 \mu \mathrm{M}$ DCVC for $12 \mathrm{~h}$. Western blotting was used to measure eIF2 $\alpha$ phosphorylation and ATF4 protein levels by a blot scanning system as described in the methods section. Graphical representation of: a relative eIF2 $\alpha$ phosphorylation and $\mathbf{b}$ relative ATF4 protein concentrations normalized to total protein. Bars represent means \pm SEM. Data were analyzed with student t-test. Asterisks indicate significant difference compared to control: $* P<0.05 . N=4$ independent experiment, with 3 replicates per treatment in each experiment. Representative western blot images for $\mathbf{c}$ eIF $2 \alpha / \mathrm{eIF} 2 \alpha$ and d ATF4 (All western blots are included in Suppl Fig. 7)
A

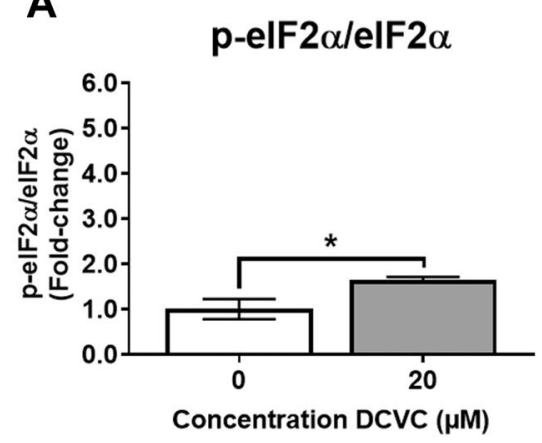

B

ATF4

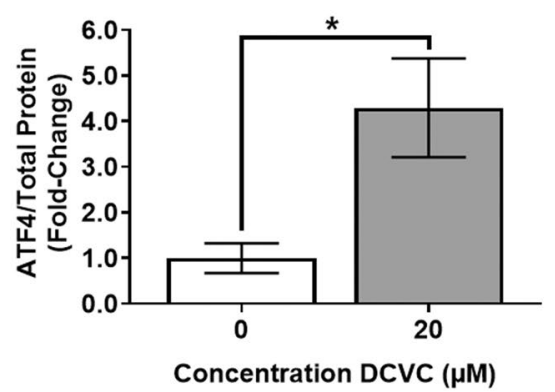

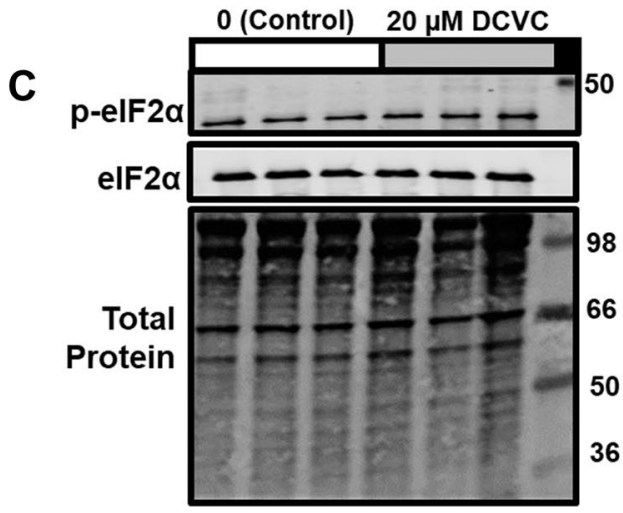

D

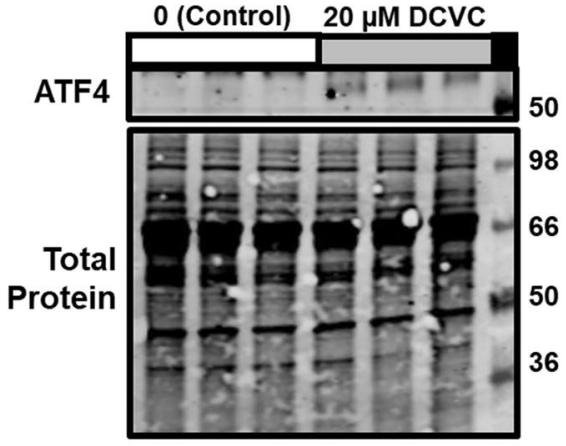




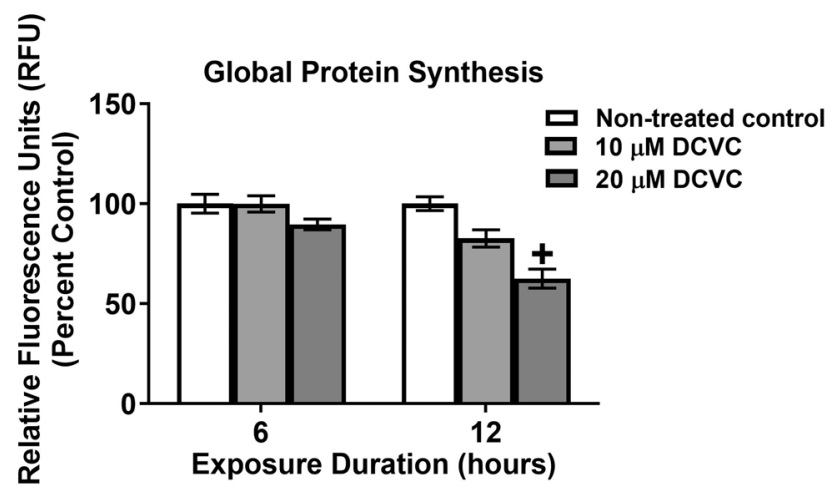

Fig. 9 DCVC effects on global protein synthesis. HTR-8/SVneo cells were treated with 0 (control) or DCVC $(10$ or $20 \mu \mathrm{M})$ for 6 or $12 \mathrm{~h}$. Protein synthesis was measured with O-propargyl-puromycin (OPP) and 5 FAM-azide fluorescent staining quantified by plate reader. Bars represent means \pm SEM. Data were analyzed by two-way ANOVA (interaction between time and treatment, $P=0.019$ ) with posthoc Tukey multiple comparisons. Plus sign indicates significant difference compared to control and $10 \mu \mathrm{M}$ DCVC within same time point: ${ }^{+} P<0.05$. $N=3$ independent experiments for each time point, with 4 replicates per treatment in each experiment

of ATF4 mRNA and protein concentrations, confirming ISR activation, as summarized in Fig. 12.

During initial ISR activation, eIF2 $\alpha$ is phosphorylated by one or more of the four enzymes in the eIF2 $\alpha$ kinase family, each of which responds to different stress stimuli: GNC2 (amino acid deprivation), PKR (viral infection), HRI (heme deficiency and ROS), and PERK (endoplasmic reticulum and mitochondrial stress) (Pakos-Zebrucka et al. 2016). In the present study, because we previously measured elevated amino acid concentrations with 12-h $20 \mu \mathrm{M}$ DCVC treatment (Elkin et al. 2020a), GNC2 is likely not the source of eIF $2 \alpha$ phosphorylation. Although not directly tested here, previous evidence suggests that mitochondrial dysfunction, which is closely associated with ER stress (Malhotra and Kaufman 2011), may be the primary stimulus driving the DCVC-induced ISR, most likely activated by eIF2 $\alpha$ kinases HRI and/or PERK (Quiros et al. 2017; Shpilka and Haynes 2018). Specifically, we previously reported that $20 \mu \mathrm{M}$ DCVC decreases mitochondrial-dependent basal, maximum, and reserve oxygen consumption rates, decreased ATP-linked respiration and coupling efficiency, increased proton leak, and dissipated mitochondrial membrane potential in HTR-8/SVneo cells (Elkin et al. 2019; Hassan et al. 2016). Moreover, it is well established that mitochondria are the key target of DCVC toxicity in kidney proximal tubular cells (Chen et al. 2001; Lash and Anders 1987; Lash et al. 2003; van de Water et al. 1993; van de Water et al. 1994; Xu et al. 2008). The ATF4-mediated gene expression pattern we observed in HTR-8/SVneo cells closely resembles the mitochondrial stress signature response reported in a multi-omics study by Quiros et al. (2017), including up-regulation of 9 amino acid biosynthesis and 5 transport genes. Moreover, we previously reported elevated SLC1A5 protein concentrations with 12-h $20 \mu \mathrm{M}$ DCVC in HTR-8/SVneo cells (Elkin et al. 2020a). Together, the available evidence suggests that mitochondrial dysfunction is likely a major stimulus driving DCVC-induced ISR activation.

Molecular signaling through the ISR has a degree of complexity that allows for tight regulation and tailored response. Although the ISR largely promotes an adaptive, pro-survival program through attenuation of global protein synthesis (Pakos-Zebrucka et al. 2016; Wortel et al. 2017), if restoration to equilibrium fails due to prolonged or severe stress, then protein synthesis may resume via amino acid biosynthesis and transport, ultimately triggering apoptosis (Han et al. 2013). Contrary to the role of amino acid biosynthesis in triggering cell death as reported by Han et al (2013), we previously demonstrated that HTR-8/SVneo cells are highly dependent on amino acids as a fuel source for successful compensatory mechanisms in response to DCVC treatment, demonstrating ISR complexity (Elkin et al. 2020a). Furthermore, ATF4-regulated gene expression plays a role in both compensation and cell death (Han et al. 2013). ATF4 regulates the gene expression of other transcription factors, while simultaneously interacting with them to co-regulate additional gene targets. For example, ATF4 regulates the expression of DDIT3 while also dimerizing with the gene's translated protein product CHOP. While adaptive genes are largely regulated by ATF4 alone, genes associated with cell death are primarily co-regulated by ATF4 and CHOP upon dimerization. (Han et al. 2013).

Here, we report evidence of conflicting ISR pro-survival and pro-apoptotic signaling in HTR-8/SVneo cells after $12 \mathrm{~h}$ of $20 \mu \mathrm{M}$ DCVC treatment, highlighting both compensatory and pathological processes at play. The differential gene expression analysis revealed many upregulated ATF4 transcriptional gene targets involved in compensatory responses including metabolism, redox balance, amino acid transport, general stress response and autophagy (Fig. 7c). On the other hand, co-regulated ATF4 and CHOP gene targets-implicated in cell death-were also upregulated including amino acid biosynthesis and apoptosis (Fig. 7c). Additionally, we observed no change in cell cycle progression or proliferation, suggesting that, overall, the cells were compensating for DCVC-induced stress after $12 \mathrm{~h}$ of exposure. These results are consistent with several of our previous studies that demonstrated simultaneous DCVC-induced pathogenic signaling and functional compensation in HTR-8/ SVneo cells. Specifically, prior work demonstrated DCVCinduced altered macronutrient and metabolic pathway utilization despite no overall change in ATP levels (Elkin et al. 2020a). Additionally, we reported elevated caspase activity despite no detectable apoptosis (Elkin et al. 2018). Taken together, these results indicate that treatment with $20 \mu \mathrm{M}$ 
A

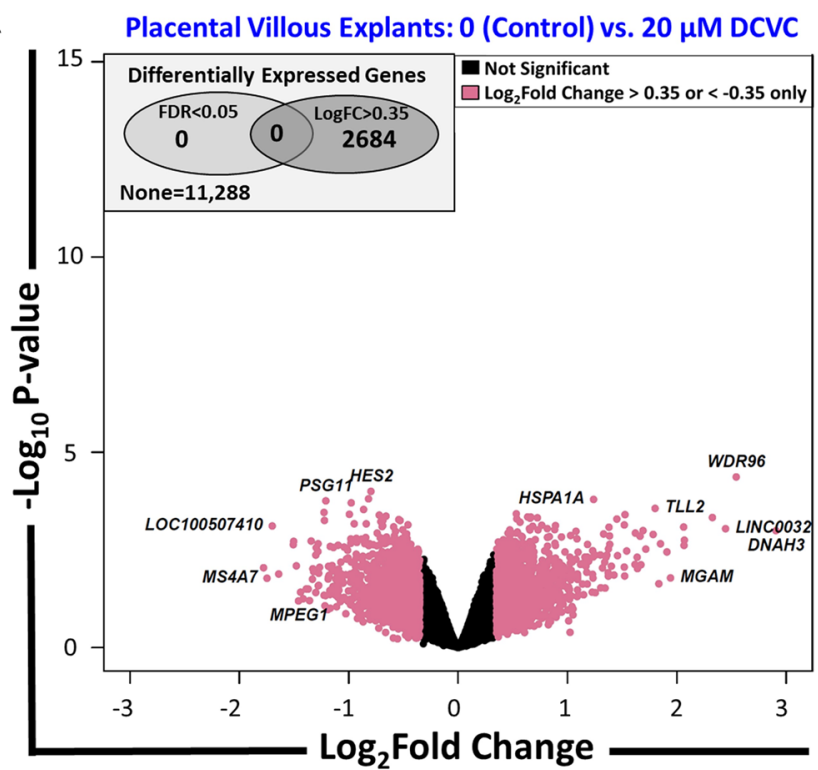

B

$12 \mathrm{~h}$ DCVC Treatment

HALLMARK Gene Sets

Pathways and Processes

\begin{tabular}{|c|c|c|}
\hline \multirow[t]{2}{*}{$\begin{array}{c}20 \\
\mu M\end{array}$} & Upregulated (5) & $\begin{array}{r}\text { TNFA SIGNALING VIA NFKB* } \\
\text { P53 PATHWAY* } \\
\text { UNFOLDED PROTEIN RESPONSE* } \\
\text { UV RESPONSE UP* } * \text { PIGNALING } \\
\text { MTORC1 SIGNALING }\end{array}$ \\
\hline & Downregulated (0) & \\
\hline
\end{tabular}

NONE

Fig. 10 Effects of DCVC on placental villous explant gene expression. First-trimester placental villous explants were treated in vitro with 0 (control) or $20 \mu \mathrm{M} \mathrm{DCVC}$ for $12 \mathrm{~h}$. Differential gene expression was measured with edgeR using quasi-likelihood general linear modeling. $N=5$ independent experiments, each performed with tissue obtained from a different placental donor. a Volcano plot comparing differential gene expression between non-treated and DCVCtreated villous explants. No genes were differentially expressed (FDR $<0.05)$. Genes fulfilling the following criteria are denoted by

DCVC for $12 \mathrm{~h}$ encompasses a critical molecular signaling transition in which, cell death signaling increases despite ongoing compensation, but without concomitant functional consequences.

In addition to specific cellular stresses, elevated ISR signaling components have been implicated in early pregnancy disorders characterized by placental abnormalities. For example, phosphorylated eIF2 $\alpha$, ATF4 protein, and/or CHOP protein were elevated in placental tissue obtained from pre-eclamptic pregnancies compared with normal pregnancies (Du et al. 2017; Fu et al. 2015). Another dark pink color: $\log \mathrm{FC}$ magnitude $>0.35$ [FC $>1.3]$. b Upregulated and downregulated gene sets from the MSigDB hallmark collection identified through GSEA as enriched after DCVC treatment. Gene sets are ordered according to the magnitude of normalized enrichment score (NES) and were considered significantly enriched with an FDR $<0.05$. Gene sets with an asterisk indicate that the pathways contained ISR/ATF4-regulated enriched genes (detailed information found in suppl. Table 6). Columns within grid denote biological categories to which gene sets belong (indicated by black square)

study reported mRNA expression suppression of an ATF4mediated placental growth factor $(P l G F)$ in placentae from women diagnosed with early-onset pre-eclampsia and confirmed those results using two trophoblast cell lines (Mizuuchi et al. 2016). Furthermore, prolonged eIF2 $\alpha$ phosphorylation decreased proliferation and invasion of trophoblast cell lines in vitro (Yung et al. 2008), a defining pathological characteristic of IUGR and pre-eclampsia (Brosens et al. 1972; Caniggia et al. 1999; Kadyrov et al. 2006; Meekins et al. 1994). Consequently, ISR activation in trophoblasts, as modeled here by HTR-8/SVneo cells, maybe a mechanism 
A

$12 \mathrm{~h}: 0$ (Control) vs. $20 \mu \mathrm{M}$ DCVC

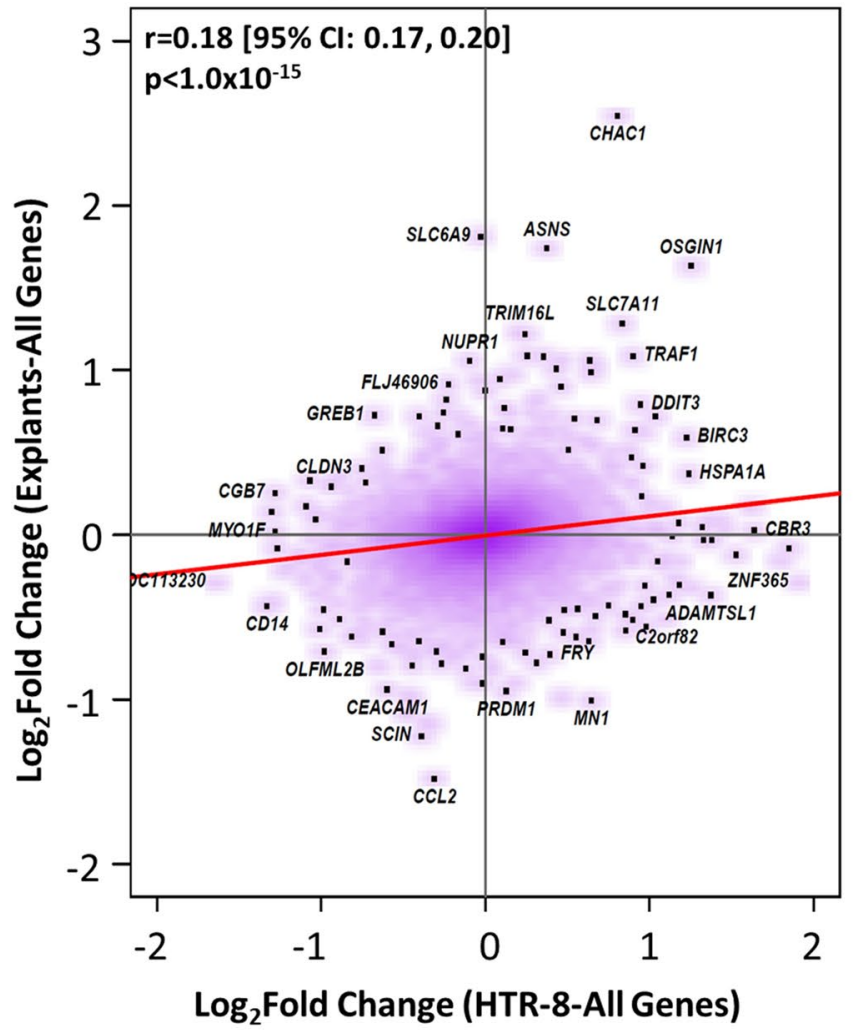

Fig. 11 Relationship between placental villous explants and HTR-8/ SVneo differential gene expression. In order to characterize the relationship between differential gene expression in first trimester villous explants and HTR-8/SVneo cells exposed to $20 \mu \mathrm{M}$ DCVC for $12 \mathrm{~h}$, respectively, Pearson's correlation coefficients $(r)$ were calculated for the pairwise comparison of $\operatorname{logFC}$ values, either for all
B

$12 \mathrm{~h}: 0$ (Control) vs. $20 \mu \mathrm{M}$ DCVC

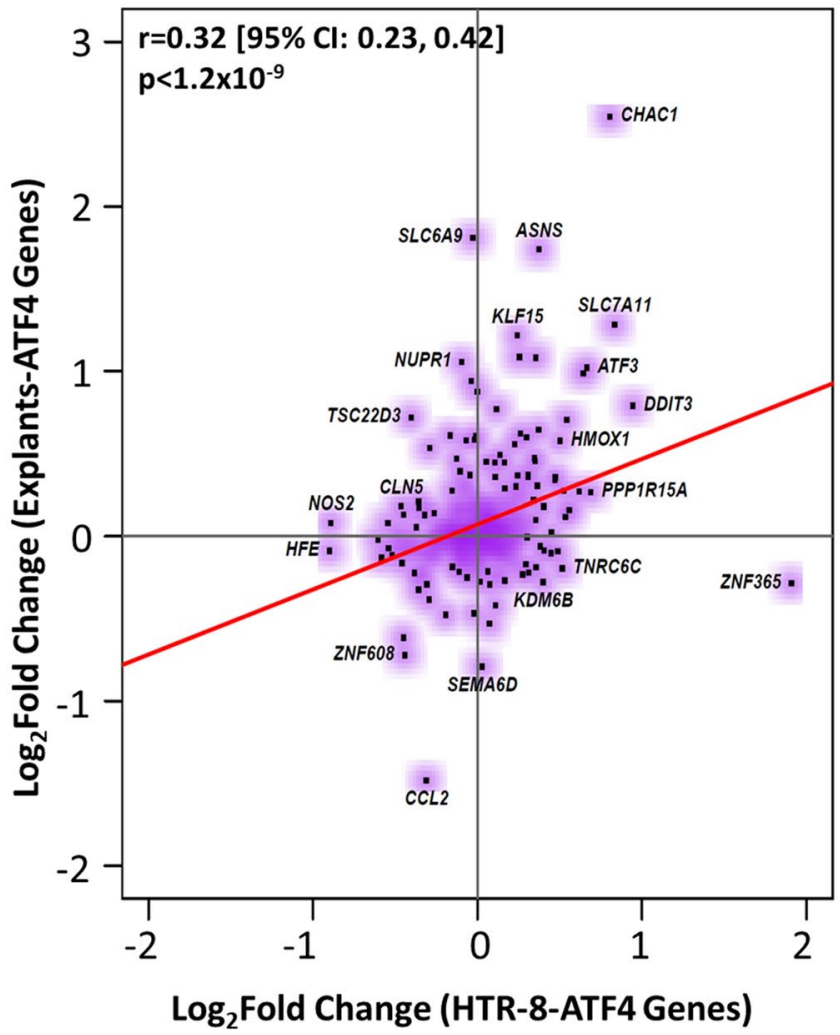

dually expressed genes $(11,913)$, or ATF4 gene targets only (383). Displayed are correlation plots of $\log \mathrm{FC}$ in gene expression between tissue and cells for 0 (control) vs. $20 \mu \mathrm{M}$ DCVC for: A) All genes $\left(P<1.0 \times 10^{-15}\right)$, or B) ATF4 gene targets only $\left(P<1.2 \times 10^{-9}\right)$. Pearson's correlation coefficient values are shown on each respective correlation plot and trend lines are displayed in red
Fig. 12 Summary of proposed DCVC-induced activation of the Integrated Stress Response. DCVC-induced mitochondrial dysfunction activates one or more of the eIF $2 \alpha$ kinases. Kinase(s) phosphorylate eIF2 $\alpha$. Phosphorylated eIF2 $\alpha$ activates transcription and translation of ATF4 and causes global protein attenuation. ATF4 transcription factor up-regulates many genes involved in biological processes necessary to restore homeostasis. ATF4 also up-regulates transcription factor CHOP, which then interacts with ATF4 to activate transcription of genes involved in cell death signaling

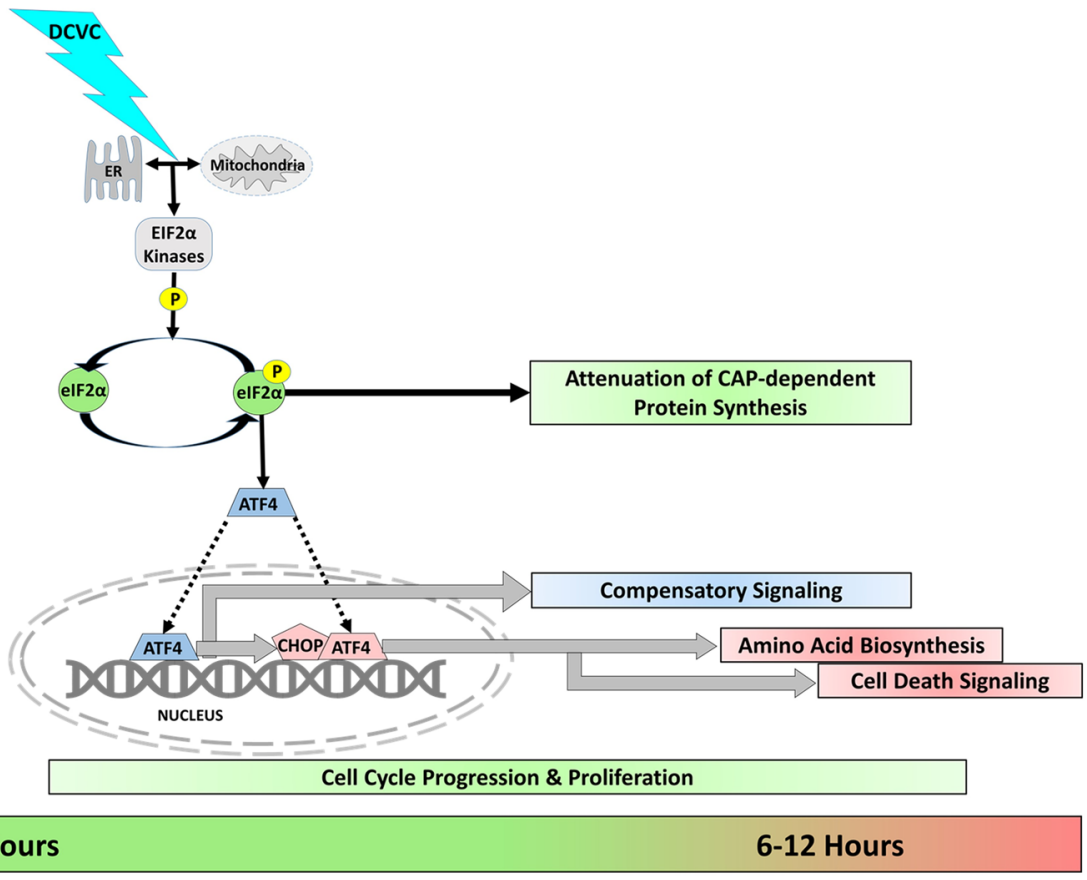


by which the TCE metabolite DCVC contributes to placental dysfunction.

\section{Villous explants versus HTR-8/SVneo differential gene expression}

In the present study, two in vitro models were utilized to measure DCVC effects on first-trimester placental gene expression: villous explants and HTR-8/SVneo cells. Due to the limited availability of first-trimester placental tissues, only one experimental comparison was made between the two models, non-treated controls versus $20 \mu \mathrm{M}$ DCVC treatment for $12 \mathrm{~h}$. Gene-specific expression levels varied considerably between tissues and cells. Treated tissues yielded no differentially expressed genes with an FDR $<0.05$, yet thousands were altered with a magnitude $\log \mathrm{FC}>0.35$ [FC $>1.3]$. On the other hand, treated cells yielded hundreds of differentially expressed genes meeting FDR criterion, but only half the number of genes were altered with a magnitude $\log \mathrm{FC}>0.35[\mathrm{FC}>1.3]$ compared to villous explants. These variable results are consistent with the relatively weak calculated correlation between genome-wide differential gene expression in tissues and cells. Differences in these results may be attributed to the tissue model containing multiple non-deconvoluted cell types, versus the cell line model containing only one genetically identical cell type (Campbell et al. 2020).

Although individual differential gene expression results differed between the models, the collective impact of differentially expressed genes - analyzed by GSEA-yielded multiple upregulated biological processes and signaling pathways that were positively enriched with DCVC treatment in both models. Moreover, two of the commonly enriched pathways, TNF $\alpha$ and $\mathrm{p} 53$, were previously reported to be upregulated by DCVC treatment in HTR-8/SVneo cells (Elkin et al. 2018). Perhaps most strikingly, the commonly enriched pathways in both models contained enrichment of genes regulated by the transcription factor ATF4. These results were supported by the moderate correlation between differential gene expression of ATF4 gene targets in tissues and cells; a correlation that was nearly twice the magnitude of that between all differential gene expression in tissues and cells. Moreover, the consistent enrichment of ATF4 gene targets across both models is indicative of ISR activation with 12-h DCVC treatment. As such, the presence of multiple cell types may hinder the ability to accurately detect differential gene expression ascribed to extravillous trophoblasts in the tissue model. Moreover, because villous explants preserve the intact villi structure, there is more variability in the underlying physiology of the two models. For example, explants retain elements of functional paracrine regulation between cells types through release of secreted signaling molecules. Therefore, explants more closely mimic in vivo conditions, than cell lines (Mannelli et al. 2015).

\section{DCVC-induced downregulation of pathways involved in embryonic development}

Biological processes and signaling pathways involved in embryonic tissue development comprised the most common category among the downregulated pathways enriched by DCVC treatment. This was a consistent finding across DCVC concentrations and exposure durations in HTR-8/ SVneo cells, but was not evident in tissues. Lending further evidence, PAX6 and SMAD3, two key transcription factors that regulate gene expression patterns in developing embryonic tissues (Liu et al. 2004; Manuel et al. 2015), were enriched with the group of genes with no expression changes at $6 \mathrm{~h}$ but downregulation after $12 \mathrm{~h}$ of $20 \mu \mathrm{M}$ DCVC treatment. Furthermore, the histone modification tri-methylation site H3K27me3, which also regulates genes expression during embryonic development, was enriched with the same group of genes. Interestingly, H3K27me3 has been shown to regulate a pattern of gene expression in the placenta that protects tissues from environmental insults (Nugent et al. 2018). These results indicate that the pattern of downregulated genes induced by DCVC treatment may be a response similar to the ISR that is intended to protect the cells and promote adaption.

\section{DCVC concentrations}

As for any toxicology study, concentrations of the toxicant tested must be carefully selected and justifiable. For the current study, concentrations of 10-20 $\mu \mathrm{M}$ DCVC were used as relevant to potential human exposure levels. The concentrations used in our study are relevant to the Occupational Safety and Health Administration (OSHA) Permissible Exposure Limit (PEL) of 100 parts-per-million (ppm) averaged over an 8-h work day (ATSDR 2016). TCE concentrations up to $229 \mathrm{ppm}$ were reported in 80 exposed workers ( $29 \%$ women) wearing aerosolized monitoring devices (29\% women) (Walker et al. 2016). Moreover, female volunteers exposed to the PEL of TCE for $4 \mathrm{~h}$ by inhalation had an average peak blood concentration of $13.4 \mu \mathrm{M}$ for the metabolic precursor to DCVC, $S$-(1,2-dichlorovinyl)glutathione (DCVG) (Lash et al. 1999), which is comparable to the concentrations used in this study. Finally, the concentrations that caused differential gene expression in our study are considerably lower than those used previously as high as $1 \mathrm{mM}$ DCVC (Chen et al. 2001; Lash et al. 2001; Lash et al. 2003; van de Water et al. 1995; Xu et al. 2008).

In addition to using low concentrations, we also investigated the effects of DCVC on placental cells for short exposure durations. Although longer exposures may more 
accurately reflect real-life exposures in vivo, this approach enabled us to evaluate the cells' initial response to DCVC exposure, otherwise lost, and elucidate compensatory mechanisms used by the cells during the process of stress-driven compensation. Nevertheless, studies exploring longer DCVC exposure durations on the placenta should also be undertaken to understand the full range of effects on the cells.

\section{Use of villous explants and HTR-8/SVneo as experimental models}

The study was conducted with a cell line and placental tissues in vitro, which may not represent biological interactions that occur in vivo. Although the tissue model keeps the villi structure intact, the critical interplay is lost ex vivo between fetal and maternal cells that play a pivotal role in placental development. Furthermore, genetic and epigenetic profile differences have been reported in HTR-8/SVneo cells when compared to primary extravillous trophoblasts cultured in similar conditions (Bilban et al. 2010; Novakovic et al. 2011). Nevertheless, HTR-8/SVneo cells express a signature combination of molecular markers particular to extravillous trophoblasts, including cytokeratin 7 and HLA-G when grown on Matrigel (Irving et al. 1995; Khan et al. 2011; Kilburn et al. 2000; Takao et al. 2011). Despite the drawbacks of using these in vitro models, both have been extensively used to investigate placental biology and the complex processes involved in placental development (Mannelli et al. 2015).

\section{Conclusion}

In summary, we used transcriptomics and gene set enrichment analyses in two first trimester placental models to identify previously unknown biological processes and molecular signaling pathways altered in response to short-term treatment with DCVC concentrations relevant to human exposures. Western blot analysis confirmed the involvement of these pathways and the functional consequences in the cell model. Although transcriptomics differed between models, GSEA demonstrated that the most substantially altered molecular signaling pathway was the ISR, and the most abundantly altered biological processes included amino acid transport, metabolism and biosynthesis, and regulation of tissue development. Evidence showed decreased global protein synthesis in agreement with ISR signaling. Despite these findings, we found no evidence for the change in cell cycle progression or proliferation under the exposure conditions used, suggesting that compensation occurred after $12 \mathrm{~h}$ of DCVC treatment. To our knowledge, this is the first report of DCVC-mediated activation of the ISR in any cell type. These findings support the biological plausibility of DCVC-induced placental toxicity, providing a compelling rationale for further studies of DCVC and its parent chemical TCE on placental pathophysiology.

Supplementary Information The online version contains supplementary material available at https://doi.org/10.1007/s00204-021-03011-5.

Acknowledgements We thank Andrea Ruszala of the University of Michigan Advanced Genomics Core for her assistance with library preparation and RNA sequencing. We also thank Maureen Sartor and Alla Karnovsky of the Omics and Bioinformatics Core of the Michigan Center on Lifestage Environmental Exposures and Disease for assistance with metabolomics statistical analyses. We thank Northland Family Planning Centers of Michigan and their patients for participating in this research study. Finally, we gratefully acknowledge Sean Harris, $\mathrm{PhD}$, Anthony Su, PhD, Faith Bjork, Kyle Campbell, JeAnna Redd and Molly Mulcahy for assistance with learning new laboratory techniques and for helpful scientific discussions, and Monica Smolinski for general lab assistance.

Author contributions ERE designed and performed the experiments, analyzed data, and wrote the manuscript. KMB and JAC assisted with experimental design, data analysis, and data interpretation. DB provided laboratory equipment and assisted with laboratory techniques, data analysis, and data interpretation. BAK obtained placental tissues and performed laboratory work on the tissues. RLC and DRA provided funding for the project and offered insight into the interpretation of the results. All authors reviewed and contributed to the manuscript and approved the final version.

Funding This work was supported by the National Institute of Environmental Health Sciences, National Institutes of Health (Grant Nos. P42 ES017198, P30 ES017885, P30 ES020957, R01 ES025574, R01 ES025531, T32 ES007062 and R01 ES028802); National Institute of Diabetes and Digestive Kidney Diseases (Grant Nos. R01 DK107535 and T32 DK071212); National Institute of Aging (Grant Nos. R01 AG055406 and P30 AG053760) and Wayne State University's Office of the Vice President for Research. The content is solely the responsibility of the authors and does not necessarily represent the official views of the NIEHS, NIDDK, NIA, or NIH.

Data availability All data have been deposited Gene Expression Omnibus (GEO) and are publicly available. GEO accession numbers are as follows: GSE154339 (HTR-8/SVneo) and GSE154489 (placental villous explants).

\section{Compliance with ethical standards}

Conflict of interest The authors declare no conflicts of interest.

Ethical approval Placental tissues were acquired as discarded tissues at the time of termination at a Michigan family planning clinic with Institutional Review Board approval (Wayne State University IRB\# 013515MP4E) and written informed consent by patients, obtained by collaborating Wayne State University physicians.

\section{References}

Andrews S (2010) FastQC: a quality control tool for high throughput sequence data. In: Bahraham Bioinformaticz. http://www.bioin formatics.babraham.ac.uk/projects/fastqc. Accessed 27 Feb 2019 
ATSDR (2016) Public Health Statement on Trichloroethylene. In: Agency for Toxic Substances and Disease Registry.https://www. atsdr.cdc.gov/ToxProfiles/tp19-c1.pdf Accessed 4 Nov 2019

ATCC (2015) American Type Culture Collection Product Sheet: HTR8/SVneo (ATCC® CRL3271TM). American Type Culture Collection

Bao XR, Ong SE, Goldberger O et al (2016) Mitochondrial dysfunction remodels one-carbon metabolism in human cells. Elife. https://doi. org/10.7554/eLife.10575

Benjamini Y, Hochberg Y (1995) Controlling the false discovery rate: A practical and powerful approach to multiple testing. J R Stat Soc: Ser B (Methodol) 57:289-300

Bilban M, Tauber S, Haslinger P et al (2010) Trophoblast invasion: assessment of cellular models using gene expression signatures. Placenta 31(11):989-996. https://doi.org/10.1016/j.placenta.2010. 08.011

Bolnick AD, Bolnick JM, Kohan-Ghadr HR et al (2017) Enhancement of trophoblast differentiation and survival by low molecular weight heparin requires heparin-binding EGF-like growth factor. Hum Reprod 32(6):1218-1229. https://doi.org/10.1093/humrep/ $\operatorname{dex} 069$

Brosens IA, Robertson WB, Dixon HG (1972) The role of the spiral arteries in the pathogenesis of preeclampsia. Obstet Gynecol Annu 1:177-191

Burton GJ, Fowden AL (2015) The placenta: a multifaceted, transient organ. Philos Trans R Soc Lond B Biol Sci 370(1663): 20140066. https://doi.org/10.1098/rstb.2014.0066

Burton GJ, Jauniaux E (2015) What is the placenta? Am J Obstet Gynecol 213(4 Suppl):S6 e1-S6-8. https://doi.org/10.1016/j. ajog.2015.07.050

Campbell KA, Colacino JA, Park SK, Bakulski KM (2020) Cell types in environmental epigenetic studies: biological and epidemiological frameworks. Curr Environ Health Rep 7(3):185-197. https:// doi.org/10.1007/s40572-020-00287-0

Caniggia I, Grisaru-Gravnosky S, Kuliszewsky M, Post M, Lye SJ (1999) Inhibition of TGF-beta 3 restores the invasive capability of extravillous trophoblasts in preeclamptic pregnancies. J Clin Invest 103(12):1641-1650. https://doi.org/10.1172/JCI6380

Chen Y, Cai J, Anders MW, Stevens JL, Jones DP (2001) Role of mitochondrial dysfunction in S-(1,2-dichlorovinyl)-1-cysteine-induced apoptosis. Toxicol Appl Pharmacol 170(3):172-180. https://doi. org/10.1006/taap.2000.9107

Chen EY, Tan CM, Kou Y et al (2013) Enrichr: interactive and collaborative HTML5 gene list enrichment analysis tool. BMC Bioinform 14:128. https://doi.org/10.1186/1471-2105-14-128

Chiu WA, Jinot J, Scott CS et al (2013) Human health effects of trichloroethylene: key findings and scientific issues. Environ Health Perspect 121(3):303-311. https://doi.org/10.1289/ehp.1205879

Davis CA, Hitz BC, Sloan CA et al (2018) The encyclopedia of DNA elements (ENCODE): data portal update. Nucleic Acids Res 46(D1):D794-D801. https://doi.org/10.1093/nar/gkx1081

Dobin A, Davis CA, Schlesinger F et al (2013) STAR: ultrafast universal RNA-seq aligner. Bioinformatics 29(1):15-21. https://doi.org/ 10.1093/bioinformatics/bts635

Du L, He F, Kuang L, Tang W, Li Y, Chen D (2017) eNOS/iNOS and endoplasmic reticulum stress-induced apoptosis in the placentas of patients with preeclampsia. J Hum Hypertens 31(1):49-55. https://doi.org/10.1038/jhh.2016.17

Durinck S, Moreau Y, Kasprzyk A et al (2005) BioMart and Bioconductor: a powerful link between biological databases and microarray data analysis. Bioinformatics 21(16):3439-3440. https://doi.org/10.1093/bioinformatics/bti525

Durinck S, Spellman PT, Birney E, Huber W (2009) Mapping identifiers for the integration of genomic datasets with the R/Bioconductor package biomaRt. Nat Protoc 4(8):1184-1191. https:// doi.org/10.1038/nprot.2009.97
Elkin ER, Harris SM, Loch-Caruso R (2018) Trichloroethylene metabolite S-(1,2-dichlorovinyl)-L-cysteine induces lipid peroxidation-associated apoptosis via the intrinsic and extrinsic apoptosis pathways in a first-trimester placental cell line. Toxicol Appl Pharmacol 338:30-42. https://doi.org/10.1016/j.taap. 2017.11.006

Elkin ER, Bridges D, Loch-Caruso R (2019) The trichloroethylene metabolite $\mathrm{S}$-(1,2-dichlorovinyl)-L-cysteine induces progressive mitochondrial dysfunction in HTR-8/SVneo trophoblasts. Toxicology. https://doi.org/10.1016/j.tox.2019.152283

Elkin ER, Bridges D, Harris SM, Loch-Caruso RK (2020a) Exposure to trichloroethylene metabolite S-(1,2-Dichlorovinyl)-L-cysteine causes compensatory changes to macronutrient utilization and energy metabolism in placental HTR-8/SVneo cells. Chem Res Toxicol 33(6):1339-1355. https://doi.org/10.1021/acs.chemrestox. 9b00356

Elkin ER, Bridges D, Harris SM, Loch-Caruso RK (2020b) Exposure to trichloroethylene metabolite S-(1,2-Dichlorovinyl)-L-cysteine causes compensatory changes to macronutrient utilization and energy metabolism in placental HTR-8/SVneo cells. Chem Res Toxicol. https://doi.org/10.1021/acs.chemrestox.9b00356

Elkin ER, Harris SM, Su AL, Lash LH, Loch-Caruso R (2020c) Placenta as a target of trichloroethylene toxicity. Environ Sci Process Impacts. https://doi.org/10.1039/c9em00537d

Encode Project Consortium (2012) An integrated encyclopedia of DNA elements in the human genome. Nature 489(7414):57-74. https:// doi.org/10.1038/nature11247

Fisher JW, Mahle D, Abbas R (1998) A human physiologically based pharmacokinetic model for trichloroethylene and its metabolites, trichloroacetic acid and free trichloroethanol. Toxicol Appl Pharmacol 152(2):339-359. https://doi.org/10.1006/taap.1998.8486

Forand SP, Lewis-Michl EL, Gomez MI (2012) Adverse birth outcomes and maternal exposure to trichloroethylene and tetrachloroethylene through soil vapor intrusion in New York State. Environ Health Perspect 120(4):616-621. https://doi.org/10.1289/ehp. 1103884

Fu J, Zhao L, Wang L, Zhu X (2015) Expression of markers of endoplasmic reticulum stress-induced apoptosis in the placenta of women with early and late onset severe pre-eclampsia. Taiwan J Obstet Gynecol 54(1):19-23. https://doi.org/10.1016/j.tjog.2014. 11.002

Graham CH, Hawley TS, Hawley RG et al (1993) Establishment and characterization of first trimester human trophoblast cells with extended lifespan. Exp Cell Res 206(2):204-211

Han J, Back SH, Hur J et al (2013) ER-stress-induced transcriptional regulation increases protein synthesis leading to cell death. Nat Cell Biol 15(5):481-490. https://doi.org/10.1038/ncb2738

Han H, Cho JW, Lee S et al (2018) TRRUST v2: an expanded reference database of human and mouse transcriptional regulatory interactions. Nucleic Acids Res 46(D1):D380-D386. https://doi.org/10. 1093/nar/gkx1013

Hassan I, Kumar AM, Park HR, Lash LH, Loch-Caruso R (2016) Reactive oxygen stimulation of interleukin-6 release in the human trophoblast cell line HTR-8/SVneo by the trichlorethylene metabolite S-(1,2-Dichloro)-L-cysteine. Biol Reprod 95(3):66. https://doi.org/10.1095/biolreprod.116.139261

Hu H, Tian M, Ding C, Yu S (2018) The C/EBP homologous protein (CHOP) transcription factor functions in endoplasmic reticulum stress-induced apoptosis and microbial infection. Front Immunol 9:3083. https://doi.org/10.3389/fimmu.2018.03083

Huckle WR (2017) Chapter two - cell- and tissue-based models for study of placental development. In: Huckle WR (ed) Progress in molecular biology and translational science, vol 145. Academic Press, Cambridge, pp 29-37

Irving JA, Lysiak JJ, Graham CH, Hearn S, Han VK, Lala PK (1995) Characteristics of trophoblast cells migrating from first trimester 
chorionic villus explants and propagated in culture. Placenta 16(5):413-433

Kadyrov M, Kingdom JC, Huppertz B (2006) Divergent trophoblast invasion and apoptosis in placental bed spiral arteries from pregnancies complicated by maternal anemia and early-onset preeclampsia/intrauterine growth restriction. Am J Obstet Gynecol 194(2):557-563. https://doi.org/10.1016/j.ajog.2005.07.035

Kaufmann P, Castellucci M (1997) Extravillous trophoblast in humans: a review. Placenta 18(Supplement 2):21-65. https://doi.org/10. 1016/S0143-4004(97)80079-3

Khan GA, Girish GV, Lala N, Di Guglielmo GM, Lala PK (2011) Decorin is a novel VEGFR-2-binding antagonist for the human extravillous trophoblast. Mol Endocrinol 25(8):1431-1443. https://doi.org/10.1210/me.2010-0426

Kilburn BA, Wang J, Duniec-Dmuchowski ZM, Leach RE, Romero R, Armant DR (2000) Extracellular matrix composition and hypoxia regulate the expression of HLA-G and integrins in a human trophoblast cell line. Biol Reprod 62(3):739-747

Kovo M, Golan A (2008) Vitro models using the human placenta to study fetal exposure to drugs clinical medicine. Reprod Health 2:15-24. https://doi.org/10.4137/CMRH.S974

Kuleshov MV, Jones MR, Rouillard AD et al (2016) Enrichr: a comprehensive gene set enrichment analysis web server 2016 update. Nucleic Acids Res 44(W1):W90-W97. https://doi.org/10.1093/ nar/gkw377

Laham S (1970) Studies on placental transfer. Trichlorethylene. IMS Ind Med Surg 39(1):46-49

Lash LH, Anders MW (1987) Mechanism of S-(1,2-dichlorovinyl)-Lcysteine- and S-(1,2-dichlorovinyl)-L-homocysteine-induced renal mitochondrial toxicity. Mol Pharmacol 32(4):549-556

Lash LH, Putt DA, Brashear WT, Abbas R, Parker JC, Fisher JW (1999) Identification of S-(1,2-dichlorovinyl)glutathione in the blood of human volunteers exposed to trichloroethylene. J Toxicol Environ Health A 56(1):1-21. https://doi.org/10.1080/00984 1099158204

Lash LH, Hueni SE, Putt DA (2001) Apoptosis, necrosis, and cell proliferation induced by S-(1,2-dichlorovinyl)-L-cysteine in primary cultures of humanproximal tubular cells. Toxicol Appl Pharmacol 177(1):1-16. https://doi.org/10.1006/taap.2001.9295

Lash LH, Putt DA, Hueni SE, Krause RJ, Elfarra AA (2003) Roles of necrosis, Apoptosis, and mitochondrial dysfunction in S-(1,2dichlorovinyl)-L-cysteine sulfoxide-induced cytotoxicity in primary cultures of human renal proximal tubular cells. J Pharmacol Exp Ther 305(3):1163-1172. https://doi.org/10.1124/jpet.102. 046185

Liao Y, Smyth GK, Shi W (2014) featureCounts: an efficient general purpose program for assigning sequence reads to genomic features. Bioinformatics 30(7):923-930. https://doi.org/10.1093/ bioinformatics/btt656

Liberzon A, Subramanian A, Pinchback R, Thorvaldsdottir H, Tamayo P, Mesirov JP (2011) Molecular signatures database (MSigDB) 30. Bioinformatics 27(12):1739-1740. https://doi.org/10.1093/ bioinformatics/btr260

Liberzon A, Birger C, Thorvaldsdottir H, Ghandi M, Mesirov JP, Tamayo P (2015) The molecular signatures database (MSigDB) hallmark gene set collection. Cell Syst 1(6):417-425. https://doi. org/10.1016/j.cels.2015.12.004

Liu Y, Festing M, Thompson JC et al (2004) Smad2 and Smad3 coordinately regulate craniofacial and endodermal development. Dev Biol 270(2):411-426. https://doi.org/10.1016/j.ydbio.2004. 03.017

Loch-Caruso R, Hassan I, Harris SM, Kumar A, Bjork F, Lash LH (2019) Trichloroethylene exposure in mid-pregnancy decreased fetal weight and increased placental markers of oxidative stress in rats. Reprod Toxicol 83:38-45. https://doi.org/10.1016/j. reprotox.2018.11.002
Lun AT, Chen Y, Smyth GK (2016) It's DE-licious: a recipe for differential expression analyses of RNA-seq experiments using quasi-likelihood methods in edgeR. Methods Mol Biol 1418:391-416. https://doi.org/10.1007/978-1-4939-3578-9_19

Malhotra JD, Kaufman RJ (2011) ER stress and its functional link to mitochondria: role in cell survival and death. Cold Spring Harb Perspect Biol 3(9):a004424. https://doi.org/10.1101/cshpe rspect.a004424

Mannelli C, Ietta F, Avanzati AM, Skarzynski D, Paulesu L (2015) Biological tools to study the effects of environmental contaminants at the feto-maternal interface. Dose Response 13(4):1559325815611902. https://doi.org/10.1177/1559325815 611902

Manuel MN, Mi D, Mason JO, Price DJ (2015) Regulation of cerebral cortical neurogenesis by the Pax6 transcription factor. Front Cell Neurosci 9:70. https://doi.org/10.3389/fncel.2015.00070

McKinney LL, Picken JC Jr, Weakley FB et al (1959) Possible toxic factor of trichloroethylene-extracted soybean oil meal3. J Am Chem Soc 81(4):909-915. https://doi.org/10.1021/ja01513a039

Meekins JW, Pijnenborg R, Hanssens M, McFadyen IR, van Asshe A (1994) A study of placental bed spiral arteries and trophoblast invasion in normal and severe pre-eclamptic pregnancies. Br J Obstet Gynaecol 101(8):669-674

Mizuuchi M, Cindrova-Davies T, Olovsson M, Charnock-Jones DS, Burton GJ, Yung HW (2016) Placental endoplasmic reticulum stress negatively regulates transcription of placental growth factor via ATF4 and ATF6beta: implications for the pathophysiology of human pregnancy complications. J Pathol 238(4):550561. https://doi.org/10.1002/path.4678

Mootha VK, Lindgren CM, Eriksson KF et al (2003) PGC-1alpharesponsive genes involved in oxidative phosphorylation are coordinately downregulated in human diabetes. Nat Genet 34(3):267-273. https://doi.org/10.1038/ng 1180

Morgan T (2014) Placental insufficiency is a leading cause of preterm labor. NeoReviews 15(12):5618-e525

Novakovic B, Gordon L, Wong NC et al (2011) Wide-ranging DNA methylation differences of primary trophoblast cell populations and derived cell lines: implications and opportunities for understanding trophoblast function. Mol Hum Reprod 17(6):344-53. https://doi.org/10.1093/molehr/gar005

Nugent BM, O’Donnell CM, Epperson CN, Bale TL (2018) Placental $\mathrm{H} 3 \mathrm{~K} 27 \mathrm{me} 3$ establishes female resilience to prenatal insults. Nat Commun 9(1):2555. https://doi.org/10.1038/ s41467-018-04992-1

Orendi K, Kivity V, Sammar M et al (2011) Placental and trophoblastic in vitro models to study preventive and therapeutic agents for preeclampsia. Placenta 32(Supplement 1):S49-S54

Pakos-Zebrucka K, Koryga I, Mnich K, Ljujic M, Samali A, Gorman AM (2016) The integrated stress response. EMBO Rep 17(10):1374-1395. https://doi.org/10.15252/embr.201642195

Pijnenborg R, Bland JM, Robertson WB, Dixon G, Brosens I (1981) The pattern of interstitial trophoblastic invasion of the myometrium in early human pregnancy. Placenta 2(4):303-16

Quiros PM, Prado MA, Zamboni N et al (2017) Multi-omics analysis identifies ATF4 as a key regulator of the mitochondrial stress response in mammals. J Cell Biol 216(7):2027-2045. https://doi. org/10.1083/jcb.201702058

R Core Team (2019) R: A language and environment for statistical computing. 3.6.1 edn. R Foundation forStatistical Computing, Vienna, Austria

Robinson MD, Oshlack A (2010) A scaling normalization method for differential expression analysis of RNA-seq data. Genome Biol 11(3):R25. https://doi.org/10.1186/gb-2010-11-3-r25

Robinson MD, McCarthy DJ, Smyth GK (2010) edgeR: a Bioconductor package for differential expression analysis of digital gene 
expression data. Bioinformatics 26(1):139-40. https://doi.org/10. 1093/bioinformatics/btp616

Ruckart PZ, Bove FJ, Maslia M (2014) Evaluation of contaminated drinking water and preterm birth, small for gestational age, and birth weight at Marine Corps Base Camp Lejeune, North Carolina: a cross-sectional study. Environ Health 13:99. https://doi.org/ 10.1186/1476-069X-13-99

Sharma K, Vu TT, Cook W et al (2018) p53-independent Noxa induction by cisplatin is regulated by ATF3/ATF4 in head and neck squamous cell carcinoma cells. Mol Oncol 12(6):788-798. https:// doi.org/10.1002/1878-0261.12172

Shpilka T, Haynes CM (2018) The mitochondrial UPR: mechanisms, physiological functions and implications in ageing. Nat Rev Mol Cell Biol 19(2):109-120. https://doi.org/10.1038/nrm.2017.110

Steegers EA, von Dadelszen P, Duvekot JJ, Pijnenborg R (2010) Preeclampsia. Lancet 376(9741):631-44. https://doi.org/10.1016/ S0140-6736(10)60279-6

Su N, Kilberg MS (2008) C/EBP homology protein (CHOP) interacts with activating transcription factor 4 (ATF4) and negatively regulates the stress-dependent induction of the asparagine synthetase gene. J Biol Chem 283(50):35106-17. https://doi.org/10.1074/jbc. M806874200

Subramanian A, Tamayo P, Mootha VK et al (2005) Gene set enrichment analysis: a knowledge-based approach for interpreting genome-wide expression profiles. Proc Natl Acad Sci USA 102(43):15545-50. https://doi.org/10.1073/pnas.0506580102

Takao T, Asanoma K, Kato K et al (2011) Isolation and characterization of human trophoblast side-population (SP) cells in primary villous cytotrophoblasts and HTR-8/SVneo cell line. PLoS ONE 6(7):e21990. https://doi.org/10.1371/journal.pone.0021990

Tetz LM, Cheng AA, Korte CS et al (2013) Mono-2-ethylhexyl phthalate induces oxidative stress responses in human placental cells in vitro. Toxicol Appl Pharmacol 268(1):47-54. https://doi.org/ 10.1016/j.taap.2013.01.020

U.S. EPA (Environmental Protection Agency) (2019a) Superfund: National Priorities List (NPL). In. https://www.epa.gov/super fund/superfund-national-priorities-list-npl Accessed 5 Nov 2019

U.S. EPA (Environmental Protection Agency) (2019b) TRI Explorer (2018 Updated Dataset (released October 2019) ) [Internet database]. In: United States Environmental Protection Agency. https:// www.epa.gov/triexplorer Accessed 4 Nov 2019

van de Water B, Zoetewey JP, de Bont HJ, Mulder GJ, Nagelkerke JF (1993) The relationship between intracellular $\mathrm{Ca} 2+$ and the mitochondrial membrane potential in isolated proximal tubular cells from rat kidney exposed to the nephrotoxin 1,2-dichlorovinylcysteine. Biochem Pharmacol 45(11):2259-67 van de Water B, Zoeteweij JP, de Bont HJ, Nagelkerke JF (1995) Inhibition of succinate:ubiquinone reductase and decrease of ubiquinol in nephrotoxiccysteine $\mathrm{S}$-conjugate-induced oxidative cell injury. Molecular pharmacology 48(5):928-37

van de Water B, Zoeteweij JP, de Bont HJ, Mulder GJ, Nagelkerke JF (1994) Role of mitochondrial Ca2+ in the oxidative stress-induced dissipation of the mitochondrial membrane potential Studies in isolated proximal tubular cells using the nephrotoxin 1,2-dichlorovinyl-L-cysteine. J Biol Chem 269(20):14546-52

Walter P, Ron D (2011) The unfolded protein response: from stress pathway to homeostatic regulation. Science 334(6059):1081-6. https://doi.org/10.1126/science.1209038

Warnes GR, Ben Bolker B, Bonebakker L, et al. (2019) gplots: Various $\mathrm{R}$ programming tools for plotting data

Walker DI, Uppal K, Zhang L et al (2016) High-resolution metabolomics of occupational exposure to trichloroethylene. Int J Epidemiol 45(5):1517-1527. https://doi.org/10.1093/ije/dyw218

Waters EM, Gerstner HB, Huff JE (1977) Trichloroethylene. I. An overview. J Toxicol Environ Health 2(3):671-707. https://doi.org/ $10.1080 / 15287397709529469$

Wortel IMN, van der Meer LT, Kilberg MS, van Leeuwen FN (2017) Surviving stress: modulation of ATF4-mediated stress responses in normal and malignant cells. Trends Endocrinol Metab 28(11):794-806. https://doi.org/10.1016/j.tem.2017.07.003

Xu F, Papanayotou I, Putt DA, Wang J, Lash LH (2008) Role of mitochondrial dysfunction in cellular responses to S-(1,2dichlorovinyl)-L-cysteine in primary cultures of human proximal tubular cells. Biochem Pharmacol 76(4):552-67. https://doi.org/ 10.1016/j.bcp.2008.05.016

Yang X, Xia R, Yue C et al (2018) ATF4 regulates CD4(+) T cell immune responses through metabolic reprogramming. Cell Rep 23(6):1754-1766. https://doi.org/10.1016/j.celrep.2018.04.032

Yung HW, Calabrese S, Hynx D et al (2008) Evidence of placental translation inhibition and endoplasmic reticulum stress in the etiology of human intrauterine growth restriction. Am J Pathol 173(2):451-62. https://doi.org/10.2353/ajpath.2008.071193

Zhao X, Liu X, Su L (2014) Parthenolide induces apoptosis via TNFRSF10B and PMAIP1 pathways in human lung cancer cells. J Exp Clin Cancer Res 33:3. https://doi.org/10.1186/ 1756-9966-33-3

Publisher's Note Springer Nature remains neutral with regard to jurisdictional claims in published maps and institutional affiliations. 